\title{
LA PROGÉNÈSE CHEZ LES TRÉMATOdES DIGÉNÉTIQUES (1)
}

\author{
Sa signification. Ses manifestations. \\ Contributions à l'étude de son déterminisme
}

\section{Par Alice BUTTNER}

\section{INTRODUC'TION}

Le phénomène de la progénèse apparaît chez les trématodes digénétiques sous des aspects très divers : tantôt, à peine ébauché, il se borne à une simple sécrétion vitelline ; tantôt, il entraîne, au contraire, une fécondité remarquable. Il se produit parfois précocement chez la cercaire encore en gestation dans la rédie ; mais, dans la majeure partie des cas, il se manifeste au stade de la métacer. caire libre ou enkystée.

En tout état de cause, se pose cet important problème : La progénèse peut-elle rendre inutile le passage par l'hôte vertébré, milieu électif considéré comme indispensable au développement normal de l'adulte chez les trématodes digénétiques?

Il faudrait pour cela que le distome fût sexuellement mûr. Jusqu'à quel point, la progénèse produit-elle cet effet ?

A. Giard (1869-1896), auquel revient la paternité du terme de "progénèse », en donne la définition suivante : «Il y a progénèse lorsque, chez un animal, la reproduction sexuée s'opère d'une façon plus ou moins prématurée, c'est-à-dire lorsque les produits sexués (œufs ou spermatozoïdes) se forment et mûrissent avant que l'être ait atteint son complet développement. » «On constate donc, soit momentanément, soit d'une façon définitive, un arrêt de croissance et de développement; l'animal progénétique a l'aspect d'une larve sexuée lorsqu'on le compare, soit à l'autre sexe, soit aux formes voisines qui ne présentent pas le phénomène de la progénèse. »

De son côté, R.-Ph. Dollfus écrit (1924) : « Nous considérons que ces phénomènes d'activité génitale précoce représentent une forme de progénèse particulière aux trématodes Digenea. Alors que, dans

(1) Travail ayant fait l'objet d'une thèse de Doctorat ès Sciences naturelles, soutenue à la Faculté des Sciences de Paris le 23 novembre 1950 et ayant obtenu la mention \& Très honorable *.

Ansales de Pailasitologie, r. XXV, $\mathrm{N}^{\circ \mathrm{s}} 5-6,1950$. 
les exemples de progénèse groupés par Alfred Giard, il y a arrêt de développement et de croissance et que le développement morphologique complet n'est pas atteint, ce phénomène n'a pas lieu chez les espèces progénétiques de trématodes. Le fonctionnement de l'appareil génital chez la métacercaire n'entraine pas l'arrêt définitif de la croissance et du développement morphologique : aussitôt que la métacercaire progénétique parvient dans son hôte définitif, elle y acquiert la forme adulte, continuant sa croissance, achevant son organogénèse et son développement morphologique. »

L'étude et les recherches expérimentales que nous allons présenter dans ce travail nous ont permis de constater que la progénèse, telle qu'elle est définie aujourd'hui, ne rend pas compte de toutes les modalités qu'elle revêt chez les trématodes; le principe d'antagonisme entre la genèse et la croissance invoquée par A. Giard ne semble pas intervenir ici, ear, ainsi que le fait observer R.-Ph. Dollfus, la progénèse n'empêche pas nécessairement la poursuite de l'organogénèse et l'achèvement de l'évolution chez un hôte définitif. Cependant, nous pensons qu'on ne saurait davantage la limiter à une tendance plus ou moins marquée vers la maturité sexuelle. Il est des cas, ainsi que nous allons le démontrer, où cette tendance se réalise effectivement chez l'hôte intermédiaire, rendant superflu le passage par l'hôte vertébré : il ne s'est produit alors ni néoténie, ni pædogénèse, tout au plus une accélération du développement, car les seuls éléments qui différencient l'adulte du stade larvaire qui le précède, à savoir la taille, le développement des gonades, la fécondité et la maturité des œufs, se trouvent réunis chez le distome progénétique. Ces formes progénétiques ont ainsi la valeur d'individus mûrs, qu'elles vivent libres dans la cavité générale de l'hôte intermédiaire ou enfermées dans un kyste.

Observons que ces cas de maturation précoce et d'accélération du développement ne sont pas particuliers aux trématodes digénétiques. Ils ont été signalés également chez des Monogenea appartenant à l'espèce Polystomum integerrimum Frœlich par E. Zeller (1872), puis par L. Gallien (1932). Zeller rapporte que si les jeunes larves de ce trématode se fixent sur de très jeunes têtards, leur croissance est beaucoup plus rapide, et, au bout de cinq semaines, elles sont sexuellement mûres, pondent des œufs et possèdent chacune leurs six ventouses postérieures ; mais l'appareil génital reste simplifié et la taille très inférieure à celle de l'adulte. L. Gallien a confirmé ces expériences et obtenu en un mois des larves sexuellement mûres, alors que le développement complet de l'adulte demande trois ans. Et cet auteur conclut : "Certains organes ou tissus n'ayant pas acquis leur structure définitive, on peut donc 
rapprocher ce cas de ceux où la maturité sexuelle est atteinte à un état plus ou moins larvaire et pour lesquels on a proposé les termes de néoténie et de progénèse. »Ces polystomes néoténiques se sont montrés très féconds. L. Gallien a étudié l'évolution de leur descendance chez des têtards plus ou moins proches de la métamorphose tt la migration des larves des branchies vers la vessie pendant que dure la métamorphose. Il admet, comme nous le discuterons nousmême dans certains cas de progénèse des trématodes digénétiques, le rôle important du cycle néoténique dans la multiplication et la propagation de l'espèce.

Citons aussi un cas de néoténie dans un autre groupe de plathelminthes, les cestodes; c'est celui d'Archigetes qui, selon Szidat (1937), serait la larve néoténique de Biacetabulum, dont la forme adulte vit chez des poissons. Ces larves néoténiques se développent chez des petits oligochètes d'eau douce, des genres Tubifex et Limnodrilus.

Cependant, ces deux derniers exemples semblent des cas de néoténie pure, et si, d'un certain point de vue, la néoténie et la progénèse posent les mêmes problèmes de biologie générale, les deux phénomènes ne peuvent être confondus, la néoténie restant toujours attachée à une organisation larvaire.

Si donc, on convient d'accorder au terme de progénèse l'acception très générale d' "activité génitale précoce », on peut admettre qu'il existe dans la nature, chez les trématodes digénétiques, plusieurs " états de progénèse », suivant que le phénomène se trouve simplement amorcé ou qu'il atteint son plein effet, au point de se substituer à l'évolution normale.

Il est des cas où la progénèse est totale et obligatoire; elle se manifeste chez tous les individus à un certain stade de leur développement ; elle les conduit à la maturité aussi sûrement que s'ils eussent séjourné chez un hôte définitif. Il est d'autres exemples où le processus est plus indécis et demeure velléitaire. Il ne frappe qu'tıne certaine proportion des individus et les oufs formés ne contiennent pas encore de miracidium mûr.

Entre ces cas de progénèse partielle, accidentelle, et ceux de progénèse totale, obligatoire, existent sans doute plusieurs états intermédiaires, célui en particulier où la progénèse serait facultative, c'est-à-dire où le cycle progénétique et le cycle normal à trois hôtes se réaliseraient concurremment chez une même espèce.

C'est tout à fait fortuitement, alors que nous nous livrions depuis plus de deux ans à l'étude de la faune parasitaire des gîtes de la région de Richelieu (Indre-et-Loire), que nous avons pu observer, chez des têtards d'Alytes obstetricans (Laur.), une métacercaire 
enkystée devenant toujours progénétique. L'intérêt biologique de cette espèce nouvelle de trématode, à laquelle nous avons donné le nom de Paralepoderma brumpti, nous a décidée, sur les conseils de notre Président de thèse, le Professeur Grassé, à abandonner nos recherches antérieures, pour nous consacrer uniquement à l'étude de la progénèse chez les trématodes.

Nos efforts ont tendu dès lors à étudier, soit expérimentalement sur du matériel vivant, soit sur coupes et matériel fixé, le plus grand nombre possible de cas de progénèse. Ce phénomène est malheu. reusement rare dans la nature et il est de nombreux helminthologistes qui ne l'ont jamais rencontré au cours de leur carrière, malgré l'abondance du matériel biologique qu'ils ont eu l'occasion d'examiner [G. Dubois (1929), C. Wesenberg-Lund (1931, p. 203)]. Nous avons eu la bonne fortune d'en réunir trois souches vivantes au laboratoire, que nous avons pu suivre avec quelques détails; les deux premières représentent des cas de progénèse totale, ce sont :

$1^{\circ}$ Paralepoderma brumpti (A. Buttner 1950), avec lequel nous avons réalisé expérimentalement, pour la première fois, un cycle abrégé sans hôte définitif et dont nous avons pu anayser le processus d'auto-fécondation.

$2^{\circ}$ Ratzia joyeuxi (E. Brumpt 1922), dont la métacercaire, toujours progénétique, se développe sous la peau des Discoglossus pictus d'Algérie. Ce parasitisme semble en voie de disparition à Alger, du fait que les discoglosses, recherchés commercialement par différents laboratoires, se font de plus en plus rares, diminuant d'autant. les chances d'infestation du mollusque- ${ }^{\text {er }}$ hôte. Nous avons actuellement 2 spécimens sur 18 (1), porteurs de ces métacercaires, dont nous avons pu suivre le développement et tenté de trouver le cycle abrégé.

$3^{\circ}$ La troisième souche appartient aux cas de progénèse partielle ; c'est celle de Pleurogenes medians (Olss.). Nous l'avons conservée au laboratoire sur un nouvel hôte intermédiaire, la larve de Sialis lutaria, particulièrement favorable, semble-t-il, au déterminisme de la progénèse, puisque, maintenue à une température constante de $25^{\circ}$ C., elle a permis en une saison précoce ( 8 avril) la production de près de 150 œufs chez une métacercaire hébergée par elle, alors que le maximum trouvé jusqu'à présent était de 64 œufs (R.-Ph. Dollfus, 1924, p. 307).

(1) C'est le $\mathrm{D}^{\mathrm{r}} \mathrm{L}$. Parrot, Sous-Directeur de l'Institut Pasteur d'Alger, qui a bien voulu nous faire récolter ces discoglosses dans les canaux d'irrigation du Jardin d'Essais, et nous tenons à lui exprimer ici notre vive reconnaissance. 
Les autres cas de progénèse que nous avons étudiés nous ont fourni divers éléments d'appréciation quant aux facteurs qui concourent à la production du phénomène et à ses variations. Ce sont : Ratzia parva (Stossich), parasite de batraciens ; métacercaire progénétique de triton, attribuée par Pontallié à Distomum crassicolle Rud. [= Brachycœlium salamandræ (Frölich)] ; Paralepoderma progeneticum A. Buttner 1950, parasite de mollusque ; Coitocæcum sp. R.-Ph. Dollfus 1938, parasite de gammares ; Astacotrema cirrigerum (K. E. von Baer 1827), parasite d'écrevisses.

Enfin, nous avons consacré un chapitre spécial aux cercaires progénétiques des Etats-Unis, chez lesquelles le même problème se pose, mais à un échelon plus précoce.

Nous avons étudié, d'autre part, certaines espèces de trématodes dont l'évolution n'est pas connue, et que leur comportement biologique semble apparenter à des métacercaires progénétiques. Tels sont Collyriclum faba (Bremser 1831), vivant dans des kystes dermiques chez les jeunes oiseaux, dont l'évolution probable se produit chez des mollusques terrestres, et Levinseniella pellucida Jägerskiold 1907, dont la transformation en adulte, réalìsée en quelques heures chez l'hôte définitif, constitue une forte présomption en faveur du caractère progénétique de sa métacercaire.

Dans ce vaste champ de recherches, nous avons dû nous limiter à l'étude de certains problèmes (évolution normale et abrégée, maturité du distome, maturation et éclosion des œufs, action de l'hôte, du milieu, de la température, etc...). Il en est d'autres (épidémiologie, spécificité, fréquence, immunité), que nous n'avons pu qu'aborder au passage ; nous souhaitons que leur évocation éveille l'attention d'autres chercheurs attirés, comme nous, par ce curieux phénomène biologique.

La progénèse chez les trématodes digénétiques n'a jamais fait l'objet d'aucun travail d'ensemble ; il nous a fallu rechercher, dans un nombre considérable de documents, les observations fragmentaires relatives à ses modalités si diverses. Nous avons eu la rare fortune d'avoir auprès de nous un maitre incomparable : le Professeur E. Brumpt (1), qui nous a fait profiter de sa grande expérience et de sa vaste érudition, et grâce auquel il nous a été permis de

(1) Qu'il nous permette de lui adresser ici l'expression de notre profonde et fidèle reconnaissance.

Nous tenons à exprimer également notre sincère gratitude au Professeur $\mathrm{H}$. Galliard, Directeur de l'Institut de Parasitologie, qui nous a toujours encouragée dans nos recherches et a suivi l'élaboration de notre travail avec une particulière bienveillance. 
consulter des publications rares, souvent uniques (1). C'est pourquoi, avant d'exposer le détail de nos expériences, nous avons pensé qu'il serait opportun de réunir, en un historique aussi complet que possible, l'étude de toutes les formes progénétiques de trématodes Digenea signalées jusqu'à ce jour, dont le genre probable a été déterminé.

\section{HISTORIQUE}

\section{A. - Métacercaires progénétiques déjà connues}

C'est K. E. von Baer qui semble avoir découvert, en 1827, (p. 553), la première métacercaire progénétique chez l' "écrevisse commune », Astacus sp., aux environs de Königsberg, surtout dans les muscles (fig. 1). Il ne dit pas avoir observé d'œufs et ne donne aucune description du distome. Bien que le cycle n'en soit pas connu, les caractères de cette métacercaire ont fait créer pour elle le genre Astacotrema E. Warren 1903, placé par Lühe dans la famille des Allocreadiidæ. Les auteurs qui ont retrouvé plus tard cette métacercaire ont toujours signalé la présence d'œufs. Il semble que ce soit C. Th. von Siebold $(1835$, p. 64 , note 1$)$ qui, le premier, ait mentionné le phénomène : il a vu la sortie des œufs à la base du cirre évaginé ; il précise que les kystes métacercariens se trouvaient dans la musculature d'Astacus astacus (L.), provenant du Chrossendorger See, près d'Heilsberg (Allemagne), en particulier dans la queue et les pinces, ainsi que dans le tissu conjonctif au voisinage des yeux et dans l'ovaire. Les autres espèces d'Astacotrema sont, d'après R.-Ph. Dollfus (communication verbale), 《 connues seulement à l'état de métacercaire progénétique ».

En 1851, à Rennes (Ille-et-Vilaine), Pontallié a signalé l'existence de nombreuses métacercaires remplies d'œufs, entre les muscles de la région hyoïdienne et à la face interne de la peau d'un amphibien urodèle, Molge marmorata Latr. Ces petits distomes enkystés furent considérés par lui comme adultes et supposés identiques à Distoma crassicolle Rud. 1809 [= Brachycolium salamandræ (Frölich 1789), Brachycoeliidæ] (fig. 2), parasite habituel de l'intestin des salamandres noires et maculées, et d'autres urodèles. Il constate cependant que son parasite ne possède pas d'épines cuticulaires et qu'il a des dimensions plus petites. D'après les renseignements bibliographiques de R.-Ph. Dollfus, K. Diesing (1858, p. 339), à prn-

(1) Nous adressons nos remerciements à M. R.-Ph. Dollfus pour les notes et documents qu'il a bien voulu nous communiquer. 


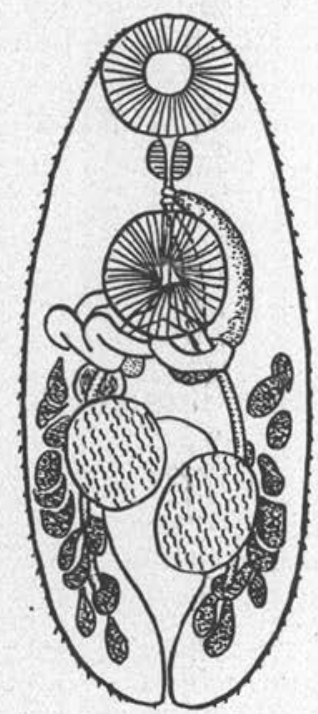

Fit. 1. - Astacotrema cirrigernm, Baer. $\times 35$ (d'après M. Lühe, 1909).

pos de D. crassicole Rud., a rappelé l'observation de Pontallié, en laissant le point de doute émis par Pontallié quant à l'identification de ce parasite à l'espèce crassicolle. M. Stossich (1889a, p. $64 ; 1889 b$, p. 5), transcrivant Diesing, a simplement indiqué, sans point de doute, que D. crassicclle Rud. avait été trouvé enkysté sous la peau et dans les muscles des tritons (1). C'est sans doute, ajoute R.-Ph. Dollfus, à cause de cette erreur de Stossich, que quelques auteurs ont signalé l'enkystement chez des batraciens de D. crassicole Rud. Le kyste transparent renfermant le ver décrit par Pontallié mesure environ $0,85 \mathrm{~mm}$. à $1 \mathrm{~mm}$. de long sur $0,70 \mathrm{~mm}$. à $0,85 \mathrm{~mm}$. de large. Le distome qu'il contient présente, dans sa moitié postérieure, une multitude d'œufs de couleur fauve, ce qui lui donne une teinte noire. Ces œufs mesurent de $0,04 \mathrm{~mm}$. à $0,05 \mathrm{~mm}$. de long sur $0,02 \mathrm{~mm}$. de large ; une faible pression suffit à faire sortir la métacercaire, dont le corps est long de $1,55 \mathrm{~mm}$. et large de $0,70 \mathrm{~mm}$. Comprimée légèrement, elle peut atteindre $2,40 \mathrm{~mm}$. sur $1 \mathrm{~mm}$. Pontallié émet l'hypothèse, pour expliquer la localisation sous-cutanée des métacercaires, d'une migration de ces larves de l'intestin vers la peau, ou encore de la pénétration des cercaires par les fentes branchiales, d'où elles se répandraient ensuite dans le tissu conjonctif des différentes parties du corps.

B. Gastaldi, en 1854 , mentionne la présence chez Rana esculenta L. (Italie), le long du

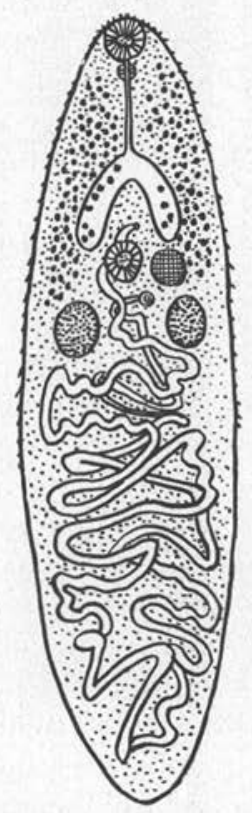

Fid. 2, - Distomum crassicolle $(=$ Brachycolium salaman$d r w)$, espèce adulte à laquelle Pontallié a identifié les métacercaires progénétiques trouvées par lui chez un triton, $\times 20$ (d'après Lühe, 1909, in Ben Dawes, 1946).

(1) Voir aussi Stossich (M.), 1889b, p. 9: Lecithodendrium crassicolle Rud. enkysté sous la peau et dans les muscles. 
tronc nerveux du plexus brachial, d'une métacercaire qu'il nomme Distomum acervocalciferum et dont l'utérus contient quelques œufs.

En 1867, F.-S. Leuckart relate qu'Oulianine, qui travaillait dans

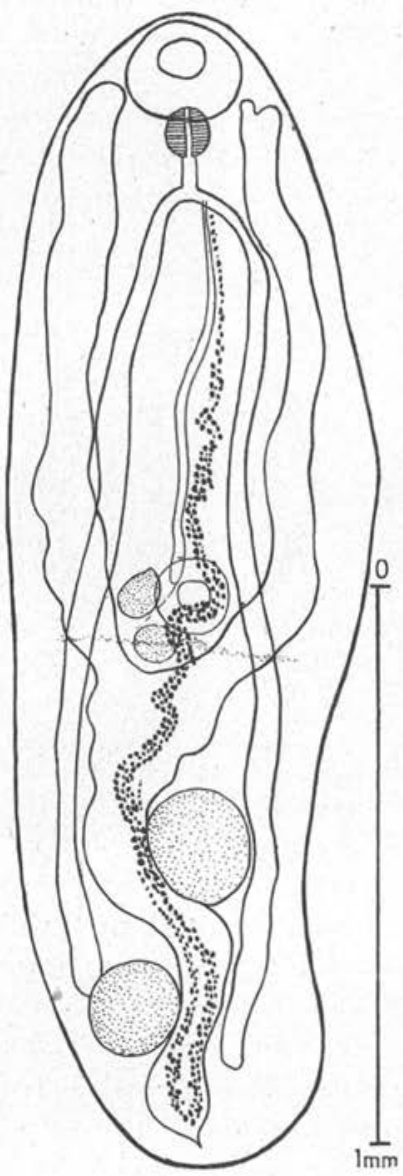

F1G. 3. - « Distome des Agrions \$, d'après une préparation originale de $\mathrm{A}$. Villot dessinée par R.-Ph. Dollfus. son laboratoire, trouva, chez des larves d'éphémères, des kystes attribuables à une cercaire virgule, Cercaria virgula Filippi. Il s'agissait de métacercaires progénétiques, et on voyait des œufs flotter entre le distome larvaire et la paroi du kyste (1).

En 1870, A. Villot observe à Grenoble des métacercaires progénétiques libres (fig. 3) chez l'imago d'insectes aquatiques, Pyrrhosoma minimum (Harris), Agrion pulchellum (Vanderlinden) et Lestes fuscus (Vanderlinden). Cet auteur considère ces métacercaires comme des vers adultes se rapprochant de Lepoderma maculosum (Rud.) et Lepoderma elegans (Rud.). D'après Villot, les plus grands individus mesuraient $3 \mathrm{~mm}$. $\times 1 \mathrm{~mm}$. et les œufs étaient longs de $10,7 \mu$ (2).

O. von Linstow (1872) signale l'autofécondation d'une métacercaire enkystée chez Gammarus pulex (L.), à laquelle il donne le nom de Distoma agamos (fig. 4). Il observe ce fait intéressant que les œufs sont mùrs et en cours de développement embryonnaire. En 1877 (p. 185), ce même auteur a rapporté à Distoma agamos Linstow une métacercaire à appareil génital moins développé, enkystée chez Asellus aquaticus L., en Allemagne.

(1) Signalons simplement ici qu'une métacercaire progénétique, celle de Pleurogenes medians (Olss.), assez fréquente chez certaines larves d'insectes, et que nous étudions en détail dans ce travail, dérive également d'une cercaire virgule.

(2) Trois spécimens du « Distome des Agrions 》 de Villot ont été examinés par R.-Ph. Dollyus qui a supposé possible leur identification à Pneumonæeces variegatus (Rud.). Dans l'utérus de ces trois spécimens, il n'y avait pas d'œufs, mais des gouttelettes de substance coquillière plus ou moins globuleuses ou ellipsoïdales. 
Sous la carapace d'Astacus leptodactylus Eschh., originaire de Russie, von Linstow (1903, p. 280-282, pl. XVII, fig. 16) a observé une métacercaire progénétique libre à laquelle il a donné le nom de Distoma reinhardi v. Linst. Il lui a trouvé une grande ressemblance avec une forme sexuellement mûre, rapportée par Reinhard en 1871 (p. 1-8, pl. V) à Distoma cirrigerum Baer.

P. Barbagallo (1901) a trouvé en Italie, sous la peau de Rana esculenta, des kystes renfermant des métacercaires progénétiques. Les œufs étaient très nombreux dans les kystes, où quelques-uns devaient être en liberté, car ils remplissaient même le tube digestif des distomes. C'est sans doute en se basant sur le travail de Stossich (1889) que Barbagallo a attribué son parasite à l'espèce Distoma crassicole Rud. [= Brachycœlium salamandræ (Brachycoeliidre) ], sans d'ailleurs justifier autrement sa dénomination.

Sous le nom de Brachymetra parva, M. Stossich a décrit (1904, p. 10-11,

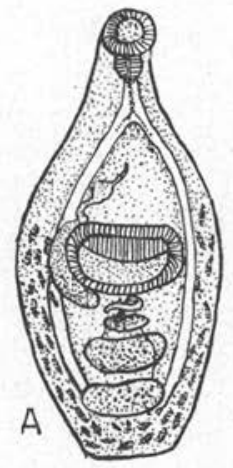

FIG. 4. - Distomum agames, von Linstow, 1872. A, le distome, $\times 45$; $B$, métacercaire progénétique (d'après von Linstow, 1872). pl. II, fig. 1) un petit distome de $1,5 \mathrm{~mm}$. à $2 \mathrm{~mm}$. sur 0,3 à $0,5 \mathrm{~mm}$., inclus dans un kyste sphérique adhérant à la surface des muscles lombaires d'une Rana esculenta L., en Istrie centrale (fig. 5). Chaque distome renfermait un petit nombre d'œufs dans l'utérus ; aussi, Stossich considéra-t-il qu'il s'agissait d'individus adultes parfaitement développés. Ce trématode, rapporté par lui à la famille des Opisthorchiidæ, présentait une morphologie interne assez particulière pour que A. Railliet (1919, p. 231) en ait fait le type d'une sous-famille, les Brachymetrinæ. Le nom générique Brachymetra a dû être abandonné, étant préemployé ; il a été remplacé par Ratzia F. Poche 1926. La sousfamille devint alors celle des Ratziinæ.

D.-F. Sinitzin (1905) a décrit des métacercaires progénétiques qu'il a attribuées à une variété de Pneumonœces variegatus (Rud.) (1) (Plagiorchiidæ), libres dans la cavité générale de larves et d'adultes de Calopteryx virgo (L.). Il a également observé des

(1) Il s’agissait de Pnenmonœces similis (A. Looss) qui a la cuticule spinulée. 


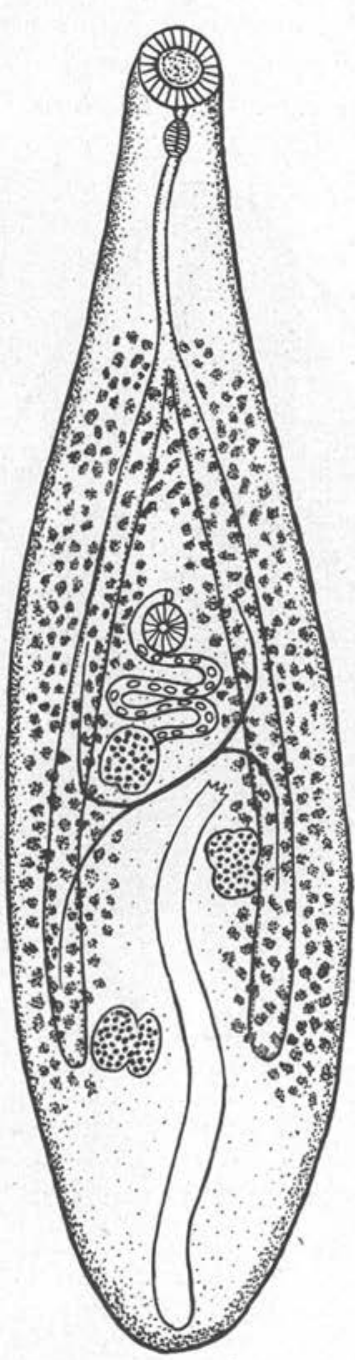

Fig. 5. - Ratzia parva (Stoss.), 1904), $\times 80$ env. (d'après Stossich, 1904).

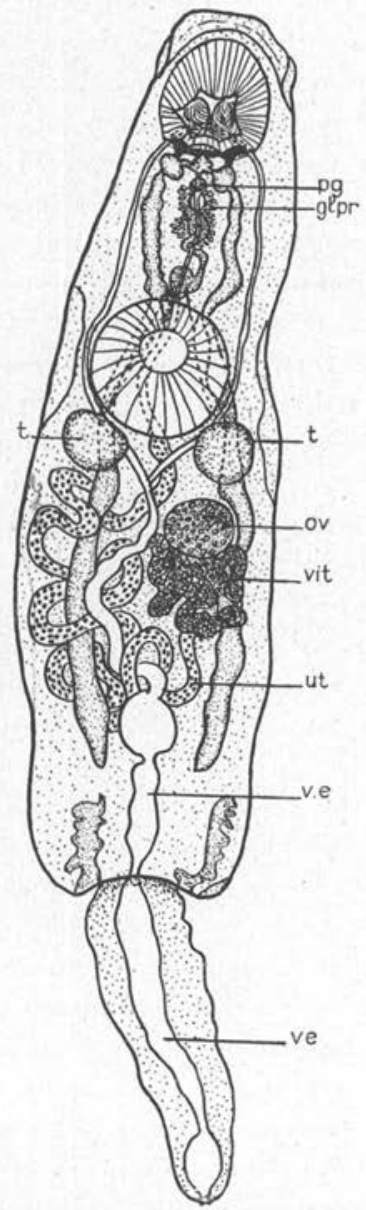

FIG. 6. - Lecithochirium rufoviride, exemplaire adulte (taille de 2,5$8 \mathrm{~mm}$. de long). gl.pr. glandes prostatiques ; ov. : ovaire ; p.g. : pore génital ; $t$. : testicules; ut. : utérus; v.e. : vésicule excrétrice; vit. : glandes vitellogènes (d'après D. O. Jones, 1944).

métacercaires progénétiques de Pleurogenes medians (Olsson) (Lecithodendriidæ), enkystées chez une larve d'agrion et chez la larve d'un petit coléoptère aquatique. 
En 1907, A. Looss publie une étude sur les distomes appartenant à la famille des Hemiuridæ. Deux espèces du genre Lecithochirium, appartenant à la sous-famille des Sterrhurinæ, évoluant chez des poissons appartenant à des familles très différentes [Lophius piscatorius L., Conger conger (L.), Anguilla vulgaris $\mathrm{L} .$, Morone labrax (L.) ], présentent le phénomène de la progénèse au stade métacercaire :

$1^{\circ}$ Lecithochirium rufoviride (Rud. 1919) (fig. 6). Les métacercaires sont enveloppées dans des kystes bruns, suspendus aux viscères (généralement l'intestin) de Blennius pholis L. Les kystes sont parfois à peine attachés ou au contraire profondément inclus dans les tissus; ils peuvent avoir des gonades bien développés et des œufs dans l'utérus, mais leur taille ne dépasse pas $2 \mathrm{~mm}$. de long.

$2^{\circ}$ Une espèce très voisine, sinon identique, Lecithochirium gravidum, a été trouvée et décrite par Looss (1907); elle s'enkyste chez des Labri$d æ$ et chez d'autres poissons ; la progénèse a été également observée, mais différents auteurs contestent sa validité en raison de son étroite ressemblance avec $L$. rufoviride at de son évolution chez d'autres espèces de poissons.

N. A. Cholodowski, cité par Skriabine (1915, p. 75), trouve chez une Phryganea sp. adulte, en Russie, une métacercaire progénétique que Skriabine attribue à Lecithodendrium chilostoma (Mehlis) (Lecithodendriidæ) (1) (fig. 7). Actuellement, cette espèce est placée

(1) Parasite fréquent de l'intestin des chauves-souris. 
dans le genre Prosthodendrium R.-Ph. Dollfus 1931. L'évolution du Prosthodendrium chilostoma (Mehlis) a été étudiée par F. J. Brown (1933). Cet auteur n'a pas trouvé la xiphidiocercaire, mais l'a reconstituée d'après de très jeunes métacercaires. Il trouva des métacercaires libres et enkystées chez des larves et des adultes de Phryganea grandis. Les métacercaires sont d'abord libres pendant plusieurs mois dans la cavité générale des larves de phrygane, puis la plupart vont s'enkyster dans les muscles thoraciques, au moment de la pupaison de l'hôte. Pendant la vie enkystée, des spermatozoïdes s'observent dans la vésicule séminale, mais il ne se forme pas d'œufs. Brown n'a fait aucune expérience sur des chauves-souris, hôte définitif habituel de ce trématode, ni sur d'autres animaux de laboratoire. Son identification est basée uniquement sur la morphologie des métacercaires âgées.

Au Canada, A. R. Cooper (1915) observe chez des Cambarus propinquus Girard et $C$. virilis Hagen, originaires de l'Ontario, des métacercaires progénétiques enkystées; toutes celles atteignant $0,86 \mathrm{~mm}$. de diamètre émettaient des œufs. Ceux-ci étaient si nombreux qu'ils occupaient plus de la moitié postérieure des plus grands spécimens, ce qui leur conférait une couleur brune permettant de les distinguer à l'œil nu. Ces métacercaires ont été attribuées à Crepidostomum cornutum (H. L. Osborn, 1903) (Allocreadiidæ), dont le cycle était déjà connu (1).

A. R. Cooper signale (1915, p. 195), sous la rubrique Allocreadium commune (Olsson), avoir trouvé chez différents poissons d'eau douce du Canada: intestins de Catostomus catostomus (Forster), Fundulus diaphanus menona (Jor. et Cop.) et dans la vésicule biliaire de Notropis cornutus (Mitchill), des vers adultes de cette espèce dont les œufs mesuraient $68 \mu \times 43 \mu, 62 \mu \times 40 \mu$ et $68 \mu \times$ $34 \mu$. Le 4 juin 1912, M. W. A. Clemens attira son attention sur une nymphe d'éphémère, Blasturus cupidus Say, présentant un ver vivant; l'examen à travers le corps très transparent de cet hôte montra de très nombreux œufs contenant un miracidium; des miracidiums libres, distribués dans tout le corps, se déplaçaient même dans les tissus mous de la nymphe, de la tête à la queue. Les œufs, évidemment rejetés par le ver, étaient identiques à ceux qui se trouvaient in utero et contenaient des miracidiums vivants ; ils mesuraient $70 \mu \times 50 \mu$; la longueur du miracidium était de $71 \mu$. Cooper crut pouvoir identifier cette métacercaire progénétique aux adultes d'Allocreadium commune trouvés par lui chez les poissons.

(1) En effet dès 1903, OsBorn avait constaté la présence, chez des écrevisses (crayfish), des métacercaires qui donnaient naissance à Bunodera cornuta Osborn, 1903. 
Deux autres nymphes d'éphémère furent trouvées plus tard porteuses de semblables métacercaires et de nombreux œufs libres. Il fut établi ultérieurement que ces métacercaires devaient être rapportées à l'espèce Plagioporus cooperi (Hunter et Bangham 1932) (1).

En 1922, E. Brumpt observe dans la peau de Discoglossus pictus, originaires du Jardin d'Essais d'Alger, des kystes très superficiels qu'un frottement énergique de la peau permettait de détacher (fig. 8). Ces métacercaires existaient à différents stades; les plus mûres, que l'extrême abondance de leurs œufs répandus dans le kyste colorait en brun foncé, tombaient spontanément au fond de l'aquarium contenant les batraciens parasités. E. Brumpt estima qu'il s’agissait de vers adultes. Il leur a donné le nom d'Opisthorchis joyeuxi n. sp. (Précis de Parasitologie, $3^{\circ}$ édition, 1922, p. 334). Ces distomes appartiennent en réalité au genre Ratzia, d'où leur désignation de Ratzia joyeuxi (Brumpt 1922).

Un an plus tard (1923, p. 332-333), Ch. Joyeux retrouvait dans les muscles de Rana esculenta var. ridibunda Pallas, de l'oasis de Gafsa (Tunisie), des kystes progénétiques de Ratzia (Brachymetra) parva (Stossich 1904). En 1927, il reprit l'étude de Ratzia joyeuxi (Brumpt 1922) et de $R$. parva (Stossich 1904), à la fois chez Discoglossus pictus du Jardin d'Essais d'Alger et chez Rana esculenta de l'oasis de Gafsa. Il ne put conclure à l'existence de différences morphologiques bien tranchées, malgré la différence habituelle de leur localisation tissulaire.

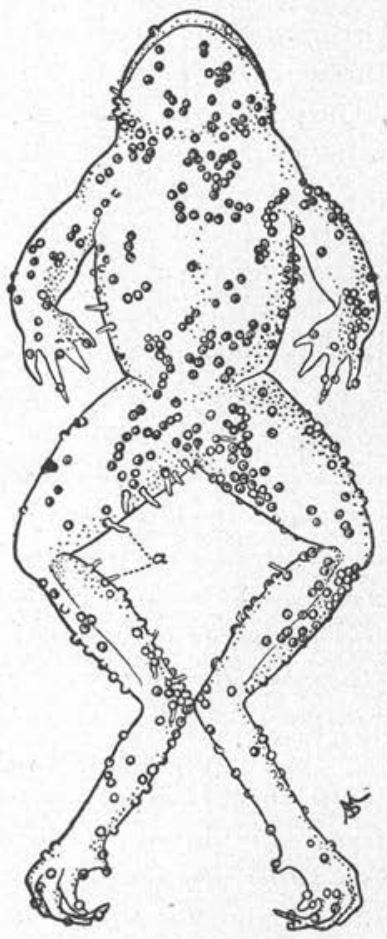

Fig. 8. - Discoglossus pictus Otth. dont les téguments renferment de nombreux kystes progénétiques de Ratzia joyeuxi (Brumpt, 1922), et les douves progénétiques sortant de ces kystes $(a), 2 / 3$ grand. nat. (d'après E. Brumpt, 1922).

R.-Ph. Dollfus (1923), à l'occasion de son étude sur le cycle évojutif des Hémiurides, rappelle que des métacercaires de Lecithochirium gravidum Looss (d'après A. Looss, 1907) et de L. rufoviride

(1) Le genre Plagioporus Stafford, créé en 1904, (Allocreadiidw) a la priorité sur le genre Lebouria Nicoll, 1909. 
Rud. (fig. 6) (d'après W. Nicoll, 1914) ont été trouvées enkystées et portant des œufs chez des poissons. Toutefois, dans une communication verbale récente, R.-Ph. Dollfus nous a signalé que, selon lui, ces métacercaires seraient plutôt de jeunes adultes dans des capsules réactionnelles.

P. Mathias, en 1924, montre que les métacercaires de Pleurogenes medians (Lecithodendriidæ), déjà connues chez diverses larves (agrion, coléoptères, Sinitzin, 1905), se rencontrent chez des Gammarus pulex (L.) du Bois de Boulogne, observation confirmée par
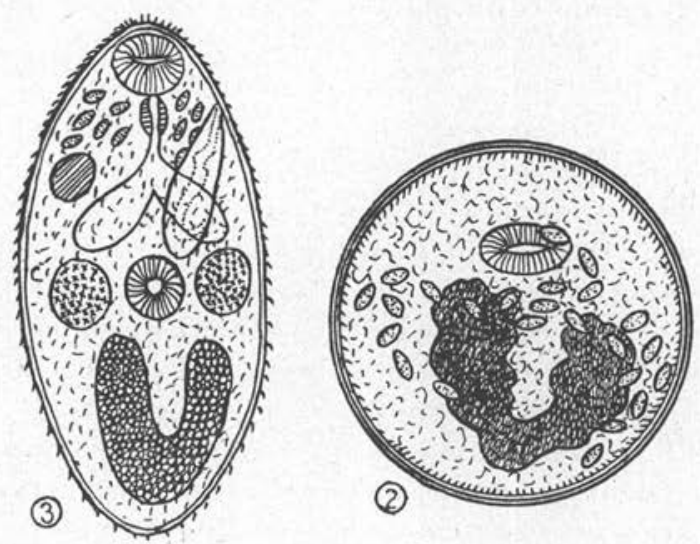

Fig. 9. - Métacercaire immature (3) et métacercaire progénćtique (2) de Pleurogenes medians (Olss.) (d'après P. Mathias, 1924), $\times 75$ env.

E. Brumpt, citée par R.-Ph. Dollfus (1924). Mathias souligne que les gammares capturés en hiver et au printemps ne renferment que des métacercaires non progénétiques (fig. $9,{ }^{3}$ ), néanmoins infectieuses pour les grenouilles. Elles viennent à maturité chez cet hôte en 12 jours, au bout desquels elles présentent de nombreux œufs jaunes dans leur utérus. Cet auteur trouve, au mois de juin, dans les mêmes gìtes, des gammares portant quelques métacercaires progénétiques (fig. $9,{ }^{2}$ ) : elles mesuraient 0,61 à $0.82 \mathrm{~mm}$. de longueur sur 0,35 à $0,45 \mathrm{~mm}$. de largeur; extraites de leur kyste, elles avaient tout à fait l'apparence de l'adulte.

Indépendamment de l'auteur précédent, R.-Ph. Dollfus (1924) observe des métacercaires progénétiques chez des Gammarus pulex (L.). Il voit dans les kystes une production d'œufs tout à fait comparable à celle observée par Sinitzin dans ses plus grands kystes d'agrion. Dollfus a compté jusqu'à 64 œufs dans l'utérus d'une même métacercaire, mais il se demande si ces œufs, chez lesquels 
il ne signale pas la présence d'un miracidium, sont capables d'évoluer.

Ce même auteur signale (1927) une métacercaire progénétique, libre dans la cavité générale d'un crustacé décapode marin, Cerataspis monstrosa Gray, qu'il reconnaît pour la métacercaire de Dinurus tornatus (Rud.) (Hemiuridæ).

O. Fuhrman signale (1928, p. 88 ), sans qu'il nous ait été possible de trouver l'origine de cette observation, la présence de métacercaires progénétiques de l'espèce Derogenes varicus (Hemiuridæ) chez des petits animaux du planeton marin, en particulier Sagitta sp. (Chætognathe).

En 1929, R.-Ph. Dollfus, ayant trouvé, chez une couleuvre du Maroc [Zamenis hippocrepis (L.)], trois exemplaires adultes d'un trématode appartenant au genre Ratzia (fig. 48), les identifie, sur des bases morphologiques, à la métacercaire progénétique signalée par M. Stossich (1904), chez Rana esculenta L., sous le nom de Brachymetra parva, ainsi qu'à celle trouvée par E. Brumpt, en 1922, sous la peau de Discoglossus pictus Otth. Cette opinion est contestée par E. Brumpt (communication verbale), par Ch. Joyeux (1943) et par nous.

En 1930, Ch. Joyeux, Rondeau du Noyer et J.-G. Baer étudient la progénèse de deux types de métacercaires progénétiques: l'une, celle de Pleurogenes medians, ver parasite de batraciens et du caméléon adulte; l'autre, attribuée par R.-Ph. Dollfus à Ratzia parva (M. Stossich), est parasite de batraciens. La cercaire de Pleurogenes medians s'enkyste chez différentes larves d'insectes ou chez des crustacés, notamment chez des Gammarus pulex (L.). Chez ces derniers, la progénèse s'observe très fréquemment dans la nature (75 p. 100 des individus), à la fin du printemps. Le nombre des œufs est peu considérable ( 30 environ), et il n'y a pas de ponte à l'intérieur du kyste.

Les auteurs n'ont pas réussi à obtenir chez des gammares conservés en captivité de métacercaires progénétiques; ils imputent cet échec à la différence existant entre le milieu expérimental et le milieu naturel, celui-ci réalisant sans doute un ensemble de conditions plus favorable au déterminisme de la progénèse. Signalons dès maintenant que, chez un hôte différent, la larve de Sialis lutaria. nous avons pu, au cours de nos expériences, obtenir en trois mois au laboratoire, dans des conditions constantes de température et d'éclairement, des métacercaires progénétiques portant plus de 150 œufs dont quelques-uns dans le kyste.

La seconde métacercaire progénétique observée par C. Joyeux, Rondeau du Noyer et J.-G. Baer, enkystée chez les discoglosses, est 
normalement progénétique; les œufs pondus s'accumulent dans le kyste. L'activité sexuelle se manifeste avec autant d'intensité que chez un adulte. Différents essais d'évolution de ces métacercaires progénétiques chez des couleuvres n'ont fait apparaitre qu'une fois la survivance d'une seule de ces métacercaires.

D. Sinitzin (1931, p. 413) dit que les métacercaires de Plagioporus siliculus Sinitzin [faux Allocreadiidæ fide Dollfus 1949 (1)], enkystées dans les muscles d'un Potamobius sp. de l'Orégon, produisent des œufs en petit nombre. C'est ainsi qu'une métacercaire de $1,5 \mathrm{~mm}$. avait émis 15 œufs, évacués entre le ver et la paroi kystique. Mais l'auteur se demande si ces œufs ont été fécondés. Il est donc probable que Sinitzin, à qui l'on doit tant de beaux travaux sur l'évolution des trématodes depuis la publication de sa thèse (1905), n'a pas vu de miracidiums formés.

L. Travassos (1931) observe dans les branchies d'un poisson, Phalloceros candomaculatus (Hensel) (Pocillidæ), des métacercaires progénétiques que, par leur morphologie, il identifie à Ascocotyle angrense L. Travassos 1915 (Heterophyidaæ), parasite habituel des oiseaux de la famille des Ardeidx. Les métacercaires sont entièrement développées, présentant la couronne d'épines caractéristique de ce groupe de distomes; chez certaines d'entre elles, il note la présence de quelques œufs, de taille inférieure à celle des œufs normaux, qu'il estima être des œufs avortés « faute de fécondation ». Cet auteur n'a pas réussi à infester expérimentalement le chat.

En 1931, E. W. Stafford signale aux Etats-Unis, chez un éphéméroptère, Hexagenia variabilis Eaton, un distome que nous supposons être une métacercaire progénétique et qu'il considère comme un adulte appartenant par sa morphologie à « Allocreadium tumidulum » (Allocreadiidæ), détermination non admise par S.-H. Hopkins (1934), car cette espèce, normalement parasite de poissons marins, appartiendrait au genre Peracreadium.

En 1932, R.-Ph. Dollfus signale pour la première fois l'existence de la progénèse chez une métacercaire, parasite d'un mollusque d'eau douce, Planorbis planorbis Linné. Ce spécimen avait été trouvé, fin avril, à la Station Grimaldi de St-Jean-de-Losne (Côte d'Or), par P. Paris. Cette métacercaire renfermait de nombreux

(1) Certains auteurs considèrent comme vrais Allocreadiidæ les espèces ayant une cercaire ophtalmoxiphidiocerque, naissant dans des rédies et se développant chez des bivalves (Spharium, Musculium, etc.) (voir S. M. Hopkins, 1934, son premier groupe d'Allocreadiida, et R.-Ph. Dollfus, 1949, Note sur Cercaria isopori A. Looss, et sur la délimitation des Allocreadioidea, p. 431-433). HunniNEN (A. V.) et CARLe (R. M.), en 1941, avaient restreint cette famille aux formes présentant des cercaires cotylicerques. En 1943, ils se sont ralliés à l'opinion d'Hopkrss qui a retiré ces espèces de la famille des Alločreadiida pour les placer dans celle des Opecolida. 
œufs et a été considérée par R.-Ph. Dollfus comme un représentant de la famille des Lepodermatidre (= Plagiorchiidx).

Les œufs brunâtres et operculés mesuraient en moyenne $38,5 \mu$ sur $19 \mu$ à maturité. Certains oufs étaient plus petits $(33,5 \mu$ à $36 \mu$ sur $18-19 \mu$ ) et, quelquefois, un embryon en voie de développement ou même un miracidium presqu'achevé étaient visibles. D'après R.-Ph. Dollfus (1950), cette métacercaire devrait être identifiée au Paralepoderma cloacicola (Max Lühe 1909) de la couleuvre à collier [Tropidonotus natrix (L.)]. L'étude morphologique que nous avons faite du parasite du cloaque de la couleuvre nous a montré, en effet, une certaine ressemblance avec la métacercaire observée par Dollfus. Toutefois, sur les dix exemplaires que nous avons examinés, neuf avaient deux cæcums s'étendant jusqu'à l'extrémité du corps, et un seul spécimen répondait exactement à la description donnée par Lühe, car les cæcums s'arrêtaient à $1 / 5$ de la partie postérieure de l'animal. Nous ne pensons pas, cependant, que la métacercaire progénétique de Planorbis planorbis, en évoluant chez une couleuvre, puisse modifier sa morphologie, car les expériences d'ingestion par des hôtes définitifs (poissons, batraciens, reptiles) de cercaires ou de métacercaires progénétiques présentant de très nombreux œufs, comme dans le cas présent, ont en général démontré que ces formes ne subissaient de modification ni dans leur morphologie, ni dans leurs dimensions [Ch. Joyeux (1930), S. H. Hopkins (1934), C. Abernathy (1937), O. Sercowa et B. Bychowsky (1940), E. E. Dickerman (1945), A. Buttner (1950)].

L. W. Wisniewski (1932) trouve, au cours de l'été 1931, chez des gammares de Bosnie, deux métacercaires progénétiques. Il récolte dix exemplaires de la première métacercaire, dont quatre seulement étaient progénétiques, chez deux Gammarus d'espèces différentes : Fontogammarus bosniacus (Schäf.) et Rivalogammarus spinicaudatus (Schäf.). Wisniewski donne à cette espèce le nom de Coitocæcum testiobliquum n. sp. (fig. $10: \mathrm{A}, \mathrm{B}, \mathrm{C}$ ), qu'il identifie à un parasite qu'il a trouvé spontanément dans l'intestin de Salmo fario L. et $S$. irideus W. Gibb. La métacercaire que représente Wisniewski est plus petite $(0,77 \mathrm{~mm} . \times 0,28 \mathrm{~mm})$ que le parasite des poissons $(0,75-1,40 \mathrm{~mm} . \times 0,90-1,25 \mathrm{~mm}$.$) , mais, comme elle ne présentait$ pas encore d'œufs et que l'auteur ne disposait que de quatre métacercaires, il est probable qu'il aurait trouvé des exemplaires plus grands, identiques à l'adulte, s'il en avait eu davantage. C'est ce qui a été observé en France, chez des gammares, pour les métacercaires de Pleurogenes medians et Coitocæcum sp. (Mathias, 1924 et 1936). L'utérus du Coitocæcum testiobliquum Wisniewski contient de 20 à 25 œufs, dont quelques-uns tombaient parfois dans l'espace 
séparant le corps de la paroi du kyste. Les dimensions de ces œufs sont les suivantes : $0,046-0,059 \mathrm{~mm}$. de long sur 0,035-0,039 $\mathrm{mm}$. de large. Il eût été intéressant d'infester des poissons indemnes avec ces métacercaires pour étudier leur évolution chez un hôte définitif.

La seconde espèce est découverte dans la cavité générale de Fontogammarus bosniacus. Sur 3.000 de ces amphipodes examinés, deux seulement présentent des métacercaires avec des œufs peu

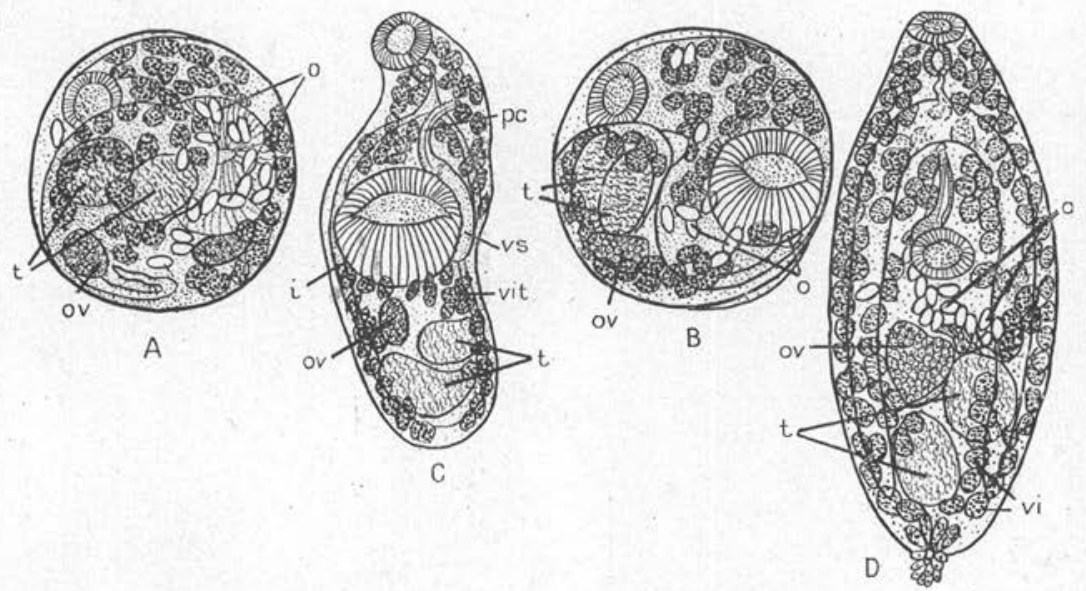

FIG. 10, - Coitocrenm testiobliquum, Wisniewski, 1933: A, B, C, métacercaires enkystées et sortie du kyste. Psilostomum progenelicum Wisniewski, 1933 : D, métacercaire progénétique. $-i$. : intestin ; $o .: \alpha$ ufs ; ov. : ovaire; p.c.: poche du cirre ; $t$. : testicule ; vit. : vitellogènes; $v . s$. : vésicule séminale. $-\times 60$ cnv. (d'après Wisniewski, 1933).

nombreux, mais bien formés, dans l'utérus, mesurant 0,050$0,057 \mathrm{~mm}$. de long sur 0,035-0,038 $\mathrm{mm}$. de large. Par leur morphologic, ces vers appartiennent au genre Psilostomum (Psilostomidx) et Wisniewski leur donne le nom de P. progeneticum n. sp. (fig. 10 , D). Le plus jeune exemplaire mesure $1 \mathrm{~mm}$. de long sur $0,42 \mathrm{~mm}$. de large et le plus âgé $1,35 \mathrm{~mm}$. sur $0,51 \mathrm{~mm}$. L'hôte définitif, s'il existe, n'est pas connu.

En 1934, V. V. Hickman décrit, sous le nom de Coitocacum anaspidis V.V. Hickman, une métacercaire (fig. 11, $c$ et $d$ ) qu'il a trouvée, à divers degrés de développement, enkystée dans toutes les parties du corps d'un amphipode anomostracé (syncaride), Anaspides tasmanix Thompson, du Mont Wellington (Tasmanie). Dans de nombreux kystes, la métacercaire était progénétique et présentait d'iinnombrables œufs qui, à maturité, contenaient un miracidium 
très mobile à l'intérieur de l'œuf. Lorsque les métacercaires mûres sont entourées de nombreux œufs dans.leur kyste, le kyste éclate et tous les œufs, ainsi que les miracidiums libérés (fig. 11, $a$ et $b$ ) se répandent dans les sinus sanguins de i'Anaspides. Les œufs peuvent ainsi parvenir dans les lamelles épipodiales et y obstruer le courant sanguin, ce qui cause la désintégration de l'appendice correspondant et permet aux œufs de tomber dans l'eau. Comme il n'y a pas de poissons dans les petits cours d'eau du Mont Wellington et que les mollusques y sont rares, v. V. Hickman a supposé que Coitocæcum anaspidis V. V. Hickman était susceptible d'accomplir la fin de son cycle dans le crustacé. Chez des Gammarus sp. des mêmes ruisseaux, V. V. Hickman a reconnu la présence de la même métacercaire progénétique enkystée; dans deux cas, les kystes contenaient des miracidiums libérés, ainsi que des œufs.

S. H. Hopkins (1934), dans son important mémoire sur les Allo-
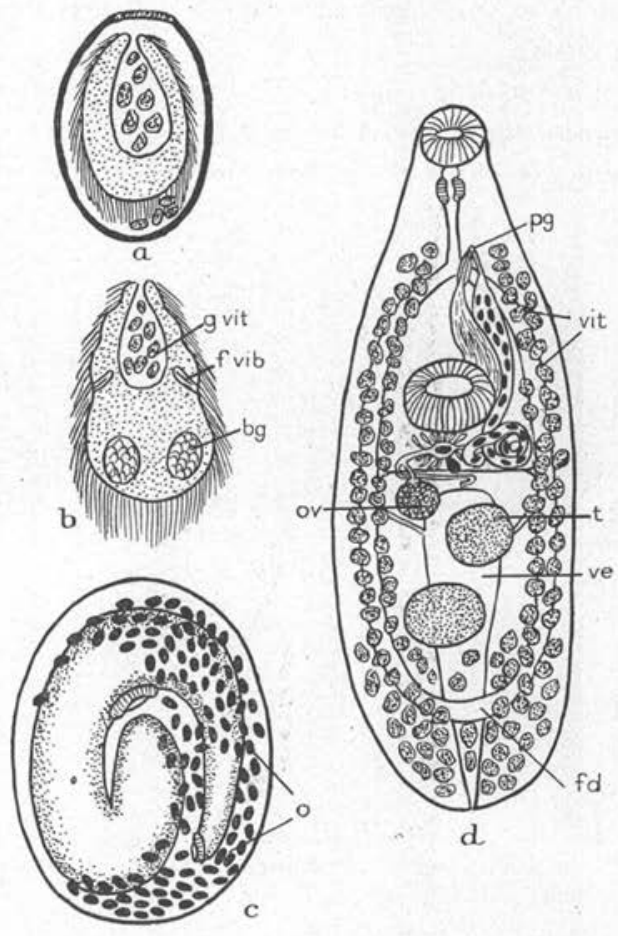

d.

FIG. 11: - Coitocrecum anasyidis, Hickman, 1934. - $a$, ouf ; $b$, miracidium ; $c$, métacercaire progénétique: $d$, adulte. - b.g. : balles germinatives; f.d.: fusion des cxeums digestifs; f.vb.: flammes vibratiles; g.vit.: granulations vitellines; ov.: ovaire; p.g.: pore génital; v.e.: vésiculc exceétrice ; vit.: vitcllogènes. Dimensions naturelles: $\propto u f: 74-83 \mu \times 46-$ $49 \mu$; miracidium : $64-83 \mu \times 37-55 \mu$; métacercaire (grands lystes) : 0,986 $1,16 \mathrm{~mm}$. × 0,638-0,812 $\mathrm{mm}$. ; adulte après fixation : $2,4-2,8 \mathrm{~mm}$. $\times 0,75$ $0,76 \mathrm{~mm}$. (d'après V. V. Hickman, 1934). creadiidæ, signale, chez plusieurs espèces d'écrevisses américaines (Cambarus), des métacercaires progénétiques possédant des yeux et dérivant d'ophtalmoxiphidiocercaires. Cet auteur les identifie à l'espèce Crepidostomum cornutum (Osborn 1904) (Allocreadiidx), dont elles ont la morphologie et les dimensions. 
En 1935, Allen Mac Intosh étudie plusieurs spécimens de métacercaires récoltés au mois de mai à Porto Rico, chez le mollusque terrestre Subulina octona. Il ne dit pas que ces métacercaires y étaient enkystées. Quoique plus petites que celles observées dans des kystes chez les poissons, elles furent rapportées par cet auteur au genre Clinostomum et peut-être à l'espèce, très commune en Amérique, C. marginatum (Rud.), parasite de divers échassiers (hérons, etc...). Deux de ces métacercaires avaient atteint leur maturité sexuelle et l'utérus de l'une d'elles était rempli d'œufs. L'auteur signale que c'est la première fois qu'une métacercaire de Clinostomum est trouvée chez un mollusque terrestre, et la seconde fois qu'une métacercaire progénétique est trouvée chez un mollusque, le premier cas ayant été étudié par R.-Ph. Dollfus chez Planorbis planorbis (L.).

Observons, à ce sujet, que Clinostomum marginatum, qui évolue habituellement à l'état larvaire chez des pulmonés aquatiques et s'enkyste chez des poissons d'eau douce, n'a jamais montré de formes progénétiques chez ces derniers animaux, malgré la longévité de ces kystes chez ces poissons. Si l'espèce progénétique étudiée par Mac Intosh est véritablement identifiable à $C$. marginatum, on pourrait admettre que le mollusque terrestre, hôte inhabituel chez lequel elle s'est enkystée, a pu jouer un rôle dans le déterminisme de la progénèse. Il se peut également, l'auteur conservant quelque doute quant à la nature de l'espèce, qu'il s'agisse d'une espèce différente de $C$. marginatum, et sensible, elle, à la progénèse.

En 1936, P. Mathias observe chez des Gammarus pulex (L.), de la rivière du Lez, aux environs de Montpellier, des kystes de trématodes contenant une métacercaire repliée sur elle-même, présentant parfois des œufs. Extraite du kyste, la métacercaire, qui atteint jusqu'à 1,3 mm. de long, a des organes génitaux bien formés, ce qui permet de déterminer à peu près sûrement le parasite. Des gammares, ingérés par des Rana temporaria L., indemnes de parasites, mettent en liberté, dans la deuxième partie de l'intestin de ces grenouilles, de jeunes trématodes à divers stades évolutifs. Ces parasites disparaissent au bout de trois jours et demi chez la grenouille et sont rejetés dans le rectum, puis à l'extérieur. D'autres gammares infestés sont donnés à des anguilles dépourvues de parasites qui montrent, du troisième au dix-septième jour, dans leur intestin, de petits trématodes actifs, semblables à ceux observés chez la grenouille. Ces mêmes métacercaires de gammares évoluent dans le tube digestif de chabots de rivière (Cottus gobio L.), indemnes de parasites. Dans les différentes expériences de cet auteur, les trématodes adultes mesuraient de 0,95 à $1,65 \mathrm{~mm}$. Chez les animaux 
tout à fait développés, l'utérus renfermait des œufs jaune clair, mesurant de 50 à $55 \mu$ de long sur $30 \mu$ de large. Mathias considère le distome obtenu comme étant Allocreadium angusticolle (Hausmann) (Allocreadiidæx). En réalité, il s'agit, comme R.-Ph. Dollfus l'a démontré (1938), en étudiant également le cycle de cet animal, d'un Coitocæcum W. Nicoll (Coitocœcidæ).

Dans une seconde note (1937), Mathias découvre la cercaire infectieuse, une cotylicercaire du type micrura, dans le corps de Neritina fluviatilis infestées à Montpellier dans la proportion de 70 à 80 p. 100 . Il infeste expérimentalement Gammarus pulex L. et Asellus aquaticus L. et obtient chez eux des kystes infectieux en trois semaines. L'auteur ne dit pas, dans cette note, si les métacercaires qu'il a obtenues expérimentalement chez ce crustacé étaient progénétiques, il dit seulement qu'elles étaient « tout à fait semblables à celles des kystes des Gammarus du Lez ». Il est possible que la progénèse ne se produise que chez les métacercaires anciennes, comme chez Pleurogenes medians.

G. Markowski (1936) observe en Pologne, chez un unique mollusque prosobranche de la Baltique (Hydrobia ventrosa), 50 métacercaires adultes de la famille des Opisthorchiidæ, mesurant $420 \mu \times$ $135 \mu$, qu'il désigne sous le nom de Metorchis progenetica (fig. 12). Toutes contenaient des œufs dont les dimensions moyennes étaient $33 \mu \times 14 \mu$ (fig. 27, pl. XIV $=$ fig. 12). C'est le troisième cas de progénèse trouvé chez un mollusque, le premier étant celui de R.-Ph. Dollfus, 1932 ; le second celui de A. Mac Intosh, 1935.

D. J. Ameel publie, en 1937, un travail qu'il avait commencé pendant l'été 1930, au Michigan. Il avait trouvé, dans une rivière de cet Etat, de nombreux Sphærium émettant des ophtalmoxiphidiocercaires. Celles-ci présentaient de grandes ressemblances avec les jeunes métacercaires de Crepidostomum cornutum (H. L. Osborn) (Allocreadiidæx), trouvées dans la région cardiaque des écrevisses de la même localité. Il put infecter facilement des Cambarus immunis avec ces cercaires. Après 24 heures, il trouvait de jeunes métacercaires enkystées, dont il ne put malheureusement suivre l'évolution en raison de l'urgence d'autres travaux. Il reprend ultérieurement ses études sur Crepidostomum cornutum (H. L. Osborn) et constate, comme S. H. Hopkins, que les vieilles métacercaires trouvées dans la nature chez les Cambarus produisent souvent un nombre considérable d'œufs d'apparence normale, mais non embryonnés, comme d'ailleurs tous ceux des Allocreadiidæ adultes. Il fait deux essais infructueux d'incubation des œufs ; ceux-ci ne produisent pas de miracidium, ce qui fait présumer à l'auteur qu'ils n'étaient peut-être pas fécondés. Une expérience témoin, faite avec 
des œufs provenant de vers adultes, récoltés dans les intestins de divers poissons, montra leur développement régulier en 15 jours, à la température de $36^{\circ} \mathrm{C}$. Ameel signale que l'adulte et les métacercaires de ce trématode ont été bien décrits par S. H. Hopkins, 1934. Expérimentalement, Ameel a obtenu des métacercaires ayant leur taille définitive en 6-8 semaines, mais il ne dit pas y avoir observé

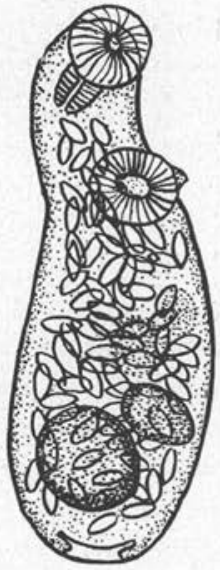

FIG. 12. - Metorchis progenetica n. sp. métacercaire provenant d'Hydrobia ventros $a, \times 135$ (d'après S. Markowski, 1936). de progénèse ; il n'a pas fait d'expérience d'évolution chez un hôte définitif, ce qui, d'ailleurs, avait été déjà effectué par Hopkins.

En étudiant également l'évolution de Crepidostomum cornutum, Clorinne Abernathy (1937) examine environ 400 Cambarus, de l'Etat d'Oklahoma, pour y déceler les métacercaires progénétiques signalées par les précédents auteurs. Chez sept exemplaires mâles et environ 80 p. 100 des femelles, ces parasites sont observés. Le nombre maximum varie de 9 chez un mâle à 113 chez une seule femelle. Ces métacercaires sont principalement localisées au voisinage immédiat des organes génitaux. Elles ressemblent aux adultes, Crepidostomum cornutum, décrits par Van Cleave et Mueller (1934), ainsi que par Hopkins (1934). Ce dernier auteur a étudié des exemplaires de Cambarus de plusieurs localités s'étendant de la Louisiane à l'Ontario. Il a constaté que les métacercaires progénétiques étaient identiques en dimensions et structure à l'animal adulte existant chez les poissons, sauf en ce qui concerne le nombre des œufs dans l'utérus et celui des spermatozoïdes dans la vésicule séminale, plus abondants chez l'adulte. Cette différence n'a pas été observée par Abernathy. A quelques exceptions près, les métacercaires étudiées par cet auteur étaient adultes et avaient déposé des œufs dans leur kyste. Contrairement à Hopkins, qui pensait que les œufs ne pouvaient se développer dans le kyste, Abernathy a vu des œufs en toute saison, à tous les stades de développement, et certains étant très près d'éclore. Afin de démontrer que cette métacercairè est identique à l'animal adulte trouvé chez les poissons, cet auteur a infesté 5 poissons rouges [Carassius auratus (L.)] et 6 poissons-chats (Ameiurus melas Rafinesque). Les poissons rouges ingérèrent respectivement $6,28,15,8$ et 24 métacercaires progénétiques et furent sacrifiés après $13,14,32,69$ et 69 heures. Ils ne montrèrent de parasites que dans l'exemplaire 2 qui présentait 
7 vers. Cependant, au cours de cette expérience, quelques œufs furent trouvés dans les selles des exemplaires 3,4 et 5 , et quatre œufs provenant de l'exemplaire 3 , sacrifié au bout de 32 heures, éclorent. Les poissons-chats, qui sont les hôtes naturels de $C$. cornutum, se sont montrés moins réfractaires. Ayant ingéré respectivement 1,29,27,17, 19 et 4 métacercaires, et examinés après 2, 6, $6,12,20$ et 28 jours, ils contenaient respectivement $0,9,4,0,4$ et 3 vers adultes. Les œufs se trouvaient en abondance dans les selles de chaque poisson. Les distomes provenant de ces poissons n'avaient pas augmenté de taille, ni changé de structure.

Dans la nature, H. E. Henderson (1938, p. 166) signale, lui aussi, avoir observé des métacercaires progénétiques de Crepidostomum cornutum chez des Cambarus nais Faxon, près de Pawnee (Oklahoma).

Dans différentes localités des environs de Shanghaï, Kuang Wu (1938) a trouvé, dans le foie et les glandes génitales de plusieurs exemplaires de deux espèces de crevettes d'eau douce, Palæmon asperulus Von Martens et $P$. nipponensis De Haan, des métacercaires progénétiques enkystées appartenant au genre Phyllodistomum M. Braun (Gorgoderidx) (fig. 13). Ces vers, semblant appartenir à une nouvelle espèce, reçoivent le nom de Phyllodistomum lesteri n. sp., en l'honneur d'H. Lester, fondateur de l'Institut de Recherches scientifiques qui porte son nom à Shanghaï.

R.-Ph. Dollfus (1938) remarque chez des Gammarus pulex (L.) et des Echinogammarus berilloni Catta, à la Station expérimentale de Richelieu (Indre-et-Loire), des métacercaires qui, par leur morphologie et après expérimentation sur des poissons (chabots, anguilles, truites arc-en-ciel), sont identifiées par lui à un Coitocæcum. Il retrouve chez des néritines la cotylicercaire signalée récemment à Montpellier par Mathias (1936) et l'identifie presque certainement à Cercaria myzura Pagent. Ces mollusques étaient infestés dans 30 à 40 p. 100 des cas.

En Nouvelle-Zélande (Provinces de Canterbury et Wellington), Coitocæcum anaspidis V. V. Hickman 1934 fut trouvé adulte par W. V. Mac Farlane (1939) dans l'intestin de divers poissons : Gobiomorphus gobioides (Cuv. Val.) (Eleotridx), Salmo fario L. juv. (Salmonidæ), Galaxias brevipennis Günther (Galaxiidæ), Galaxias attenuatus (Jenyns) et anguilles indéterminées. Mac Farlane trouva la cercaire cotylicerque correspondante dans des sporocystes parasitant deux espèces de Potamopyrgus (fig. 14, A, B, C) et la métacercaire enkystée dans l'hémocèle de l'amphidode Paracalliope fluviatilis Thompson. L'adulte normal est, d'après les mesures de W. V. Mac Farlane, plus petit que les plus grandes métacercaires 
progénétiques de V.V. Hickman. Le miracidium des œufs de l'adulte ne diffère pas de celui des œufs des métacercaires progénétiques de Hickman. Dans les métacercaires progénétiques enkystées chez Paracalliope, W. V. Mac Farlane a compté jusqu'à 200 œufs,

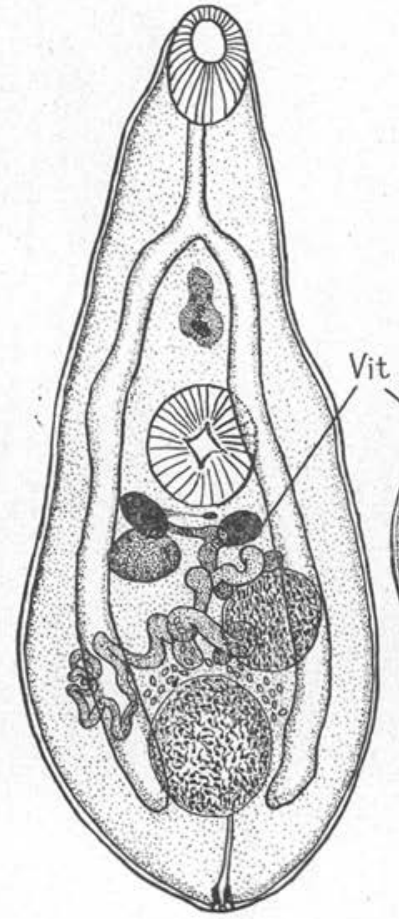

A

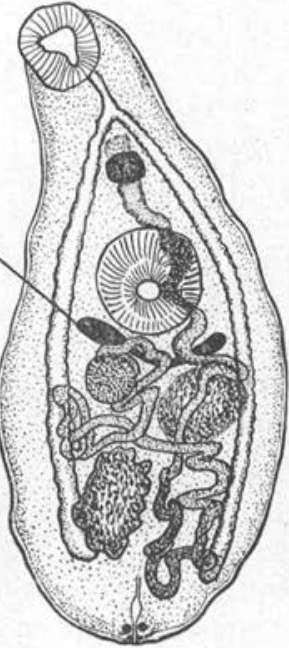

C

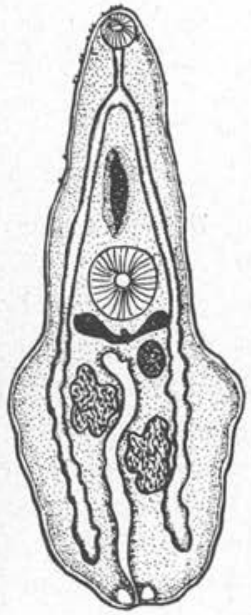

B

Fıg. 13. - Métacercaires de Phyllodistomum lesteri, Kuang Wu, 1938 ; trouvées chez des crevettes d'eau douce. A, métacercaire mùre avec testicules massifs, provenant du foie; C, spécimen mûr, avec testicules lobés (foie) ; B, spécikien immature avec testicules lobés, provenant des glandes génitales, montrant la vésicule excrétrice, les épines cuticulaires. Vit. : glandes vitellogènes. Tailles (longueur) : A : $5 \mathrm{~mm} ., 3$; B : $2 \mathrm{~mm}, 7$; C : $4 \mathrm{~mm} ., 2$. (D'après Kuang Wu, 1938).

mais l'appareil mâle ne paraissant pas fonctionnel, W. V. Mac Farlane a supposé possible que les miracidiums produits soient parthénogénétiques. Avec des Paracalliope, W. V. Mac Farlane a expérimentalement infesté Gobiomorphus gobioides (Cuv. Val.).

W. W. Crawford (1940) trouve, dans la cavité générale d'un coléoptère du genre Dytiscus, des métacercaires non enkystées ayant atteint leur maturité sexuelle. Elles contenaient des centaines d'œufs qui commencèrent à éclore 14 jours plus tard. Il obtient la 
pénétration des miracidiums chez des Pisidium. Il observa ensuite des rédies et des cercaires immatures ; mais, comme il ne dit pas que les Pisidium utilisés étaient des mollusques neufs d'élevage, il est plus vraisemblable que ces formes larvaires provenaient d'une infestation spontanée fréquente dans la nature. Cet auteur estima que la métacercaire progénétique observée par lui était un Allocreadium, effectuant peutêtre son cycle chez deux hôtes invertébrés seulement.

En 1940, O. Sercowa et Bychowsky observent en Russie, chez Bithynia tentaculata, des métacercaires progénétiques qu'ils décrivent sous le nom d'Asymphilodora progenetica (Monorchiidx). Ceci est le quatrième cas de progénèse signalé chez un mollusque.

Ces métacercaires ingérées par différents poissons (Rutilus rutilus, Carassius) y vivent six jours. Il faut croire que les auteurs n'ont pas noté de différence entre les métacercaires du mollusque et les vers des poissons, puisqu'ils estiment que les unes et les autres sont des distomes adultes. Ils trouvent chez des Bithynia ten-
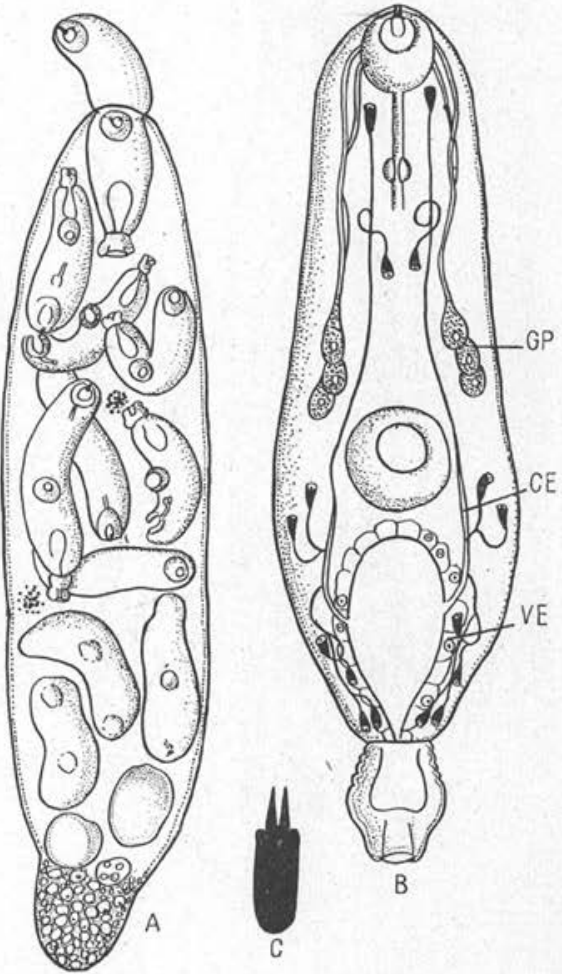

Fig. 14. - Coilocacum anaspidis : A, sporocyste ; $B$, cercaire, face ventrale ; $C$, stylet. - GP, glandes de pénétration; CE, canal exercteur; VE, vésicule excrétrice. Tailles: A : $1,20 \times 0 \mathrm{~mm}$., 50 ; B : $0,27 \times 0 \mathrm{~mm}$., 09 ; C : $0,015 \mathrm{~mm}$. de long. (D'après W. V. Mac Farlane, 1939).

taculata des cercariæums, naissant dans des rédies et s'enkystant expérimentalement chez des mollusques de la même espèce placés dans le même aquarium, en donnant des métacercaires progénétiques. Mais ils n'ont pas fait d'infestations expérimentales de mollusques à partir des œufs de ces métacercaires progénétiques.

A. V. Hunninen et Cable R. M. (1940) signalent des métacercaires évacuant des œufs dans leur kyste chez des Amphipodes marins 
Carinogammarus mucronatus (Say), Amphito longimana (Smith)], produites par des cotylicercaires naissant dans des sporocystes chez Mitrella lunata (Say) (gastropode marin prosobranche cténobranche). Ces auteurs identifient leurs métacercaires au trématode adulte, Anisoporus manteri

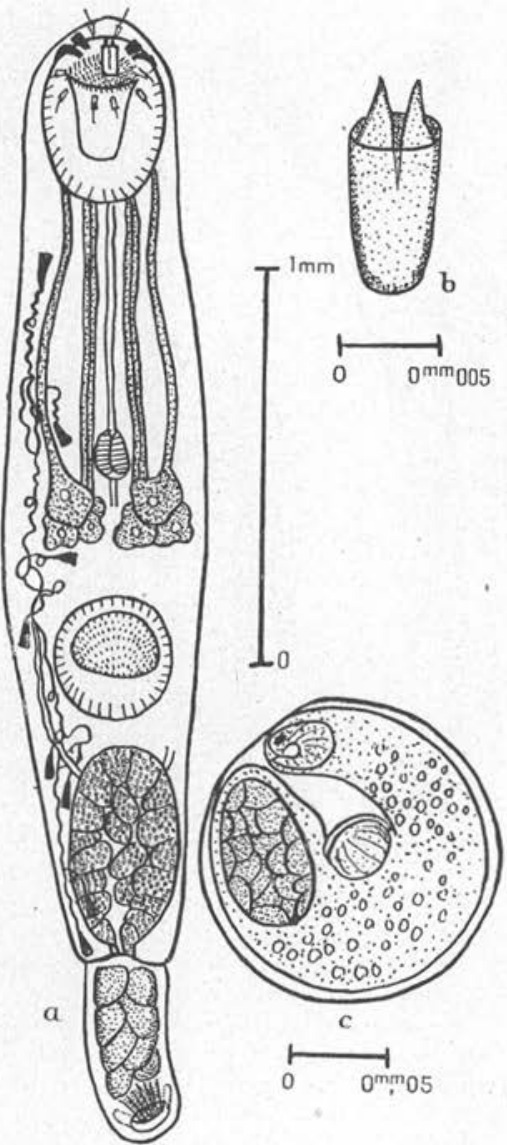

Fig. 15. - Anisoporus manteri. a, cercaire, face ventralc ; $b$, stylet, vue dorsale ; $c$, métacercaire de 2 jours (d'après Hunninen et Cable, 1941). n. sp. (Opecælidæ) (fig. 15 et 16), qu'ils placent à tort dans les Allocreadiidæ. Cette famille, qui ne possède que des ophtalmoxiphidiocercaires, ne comporte aucun genre ayant des cercaires cotylicerques. Les Anisoporus manteri Hunninen et Cable adultes se trouvent dans la nature chez six espèces de poissons marins des Etats-Unis.

Ces mêmes auteurs (1943) trouvent, chez Gammarus sp., Carinogammarus mucronatus (Say) et Amphitoe longimana Smith, des métacercaires dont les plus grandes sont souvent progénétiques. Co $\mathrm{m} \mathrm{m} \mathrm{e}$ dans le cas précédent, il s'agit d'une cotylicercaire, naissant dans des sporocystes, chez Littorina rudis. Hunninen et Cable considèrent ces métacercaires comme appartenant à l'espèce Podocotyle atomon (Rud.), de la famllle des Opecolidær. P. atomon (Rud.) se trouve à l'état adulte chez un grand nombre d'espèces de téléostéens marins.

W. V. Mac Farlane (1945) découvre, dans les muscles de différents poissons d'eau douce (Gobiomorphus, Galaxias et jeunes Salmo fario L.) de Nouvelle-Zélande, des métacercaires dont quelques-unes sont progénétiques et qui émettent parfois des œufs dans leur kyste. Les œufs se développent jusqu'au miracidium mobile, mais ils n'éclosent pas. Ces métacercaires proviennent de pleurolophocercaires, naissant 
dans des rédies chez le mollusque Potamopyrgus badia Gould 1848, ainsi que chez d'autres espèces de Potamopyrgus (prosobranche d'eau douce).

D'après cet auteur, ces métacercaires sont identiques au trématode adulte Telogaster opisthorchis n. g., n. sp. (Heterophyida), trouvé par lui dans l'intestin d'anguilles, Anguilla dieffenbachi et $A$. australis schmittii de Nouvelle-Zélande. Mac Farlane pense que les œufs n'éclosent pas dans le milieu extérieur, mais dans l'intestin des Potamopyrgus. L'auteur a observé dans ses expériences la pénétration de la cercaire dans des fragments de muscles de poissons ; il n'a pas essayé d'infester des mollusques avec les œufs des métacercaires progénétiques ou des adultes de poisson.

$$
* *
$$

Dans le tableau I, un état récapitulatif de toutes tes métacercaires progénétiques actuellement connues, rapportées par les auteurs à un genre déterminé, donnera une idée approximative de l'ensem-

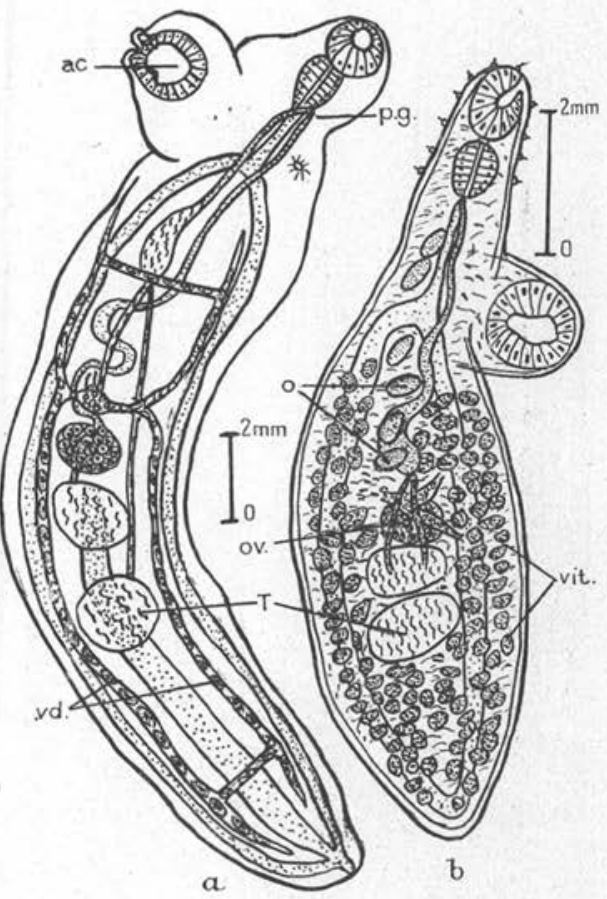

Fiv. 16. - Anisoporus manteri. a, adulte, face ventrale; $b$, adulte, face dorsale. ac. : acetabulum; w. : oufs : o\%. : ovaire ; p.g. : pore génital; $t$. : testieules ; vd. : vitelloductes ; vil.: vitelloģines (d'après Hunninen et Cable, 1941). ble des familles les plus fréquemment atteintes par la progénèse.

$$
* *
$$

Nous ne saurions achever cet historique sans signaler que les métacercaires ne sont pas les seules formes larvaires de trématodes susceptibles de présenter le phénomène de la progénèse.

Des cercaires progénétiques ont été observées dans la nature. 


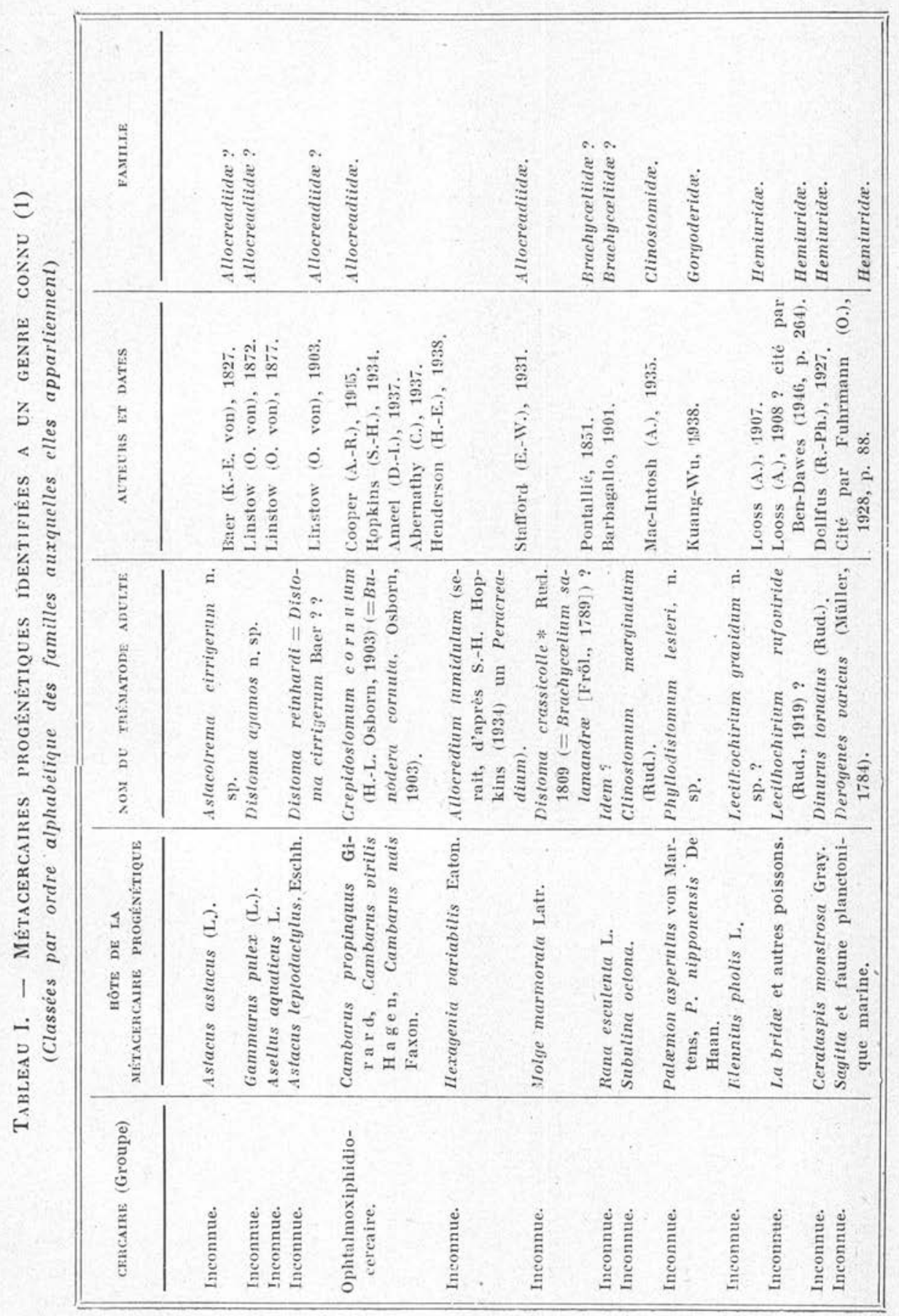




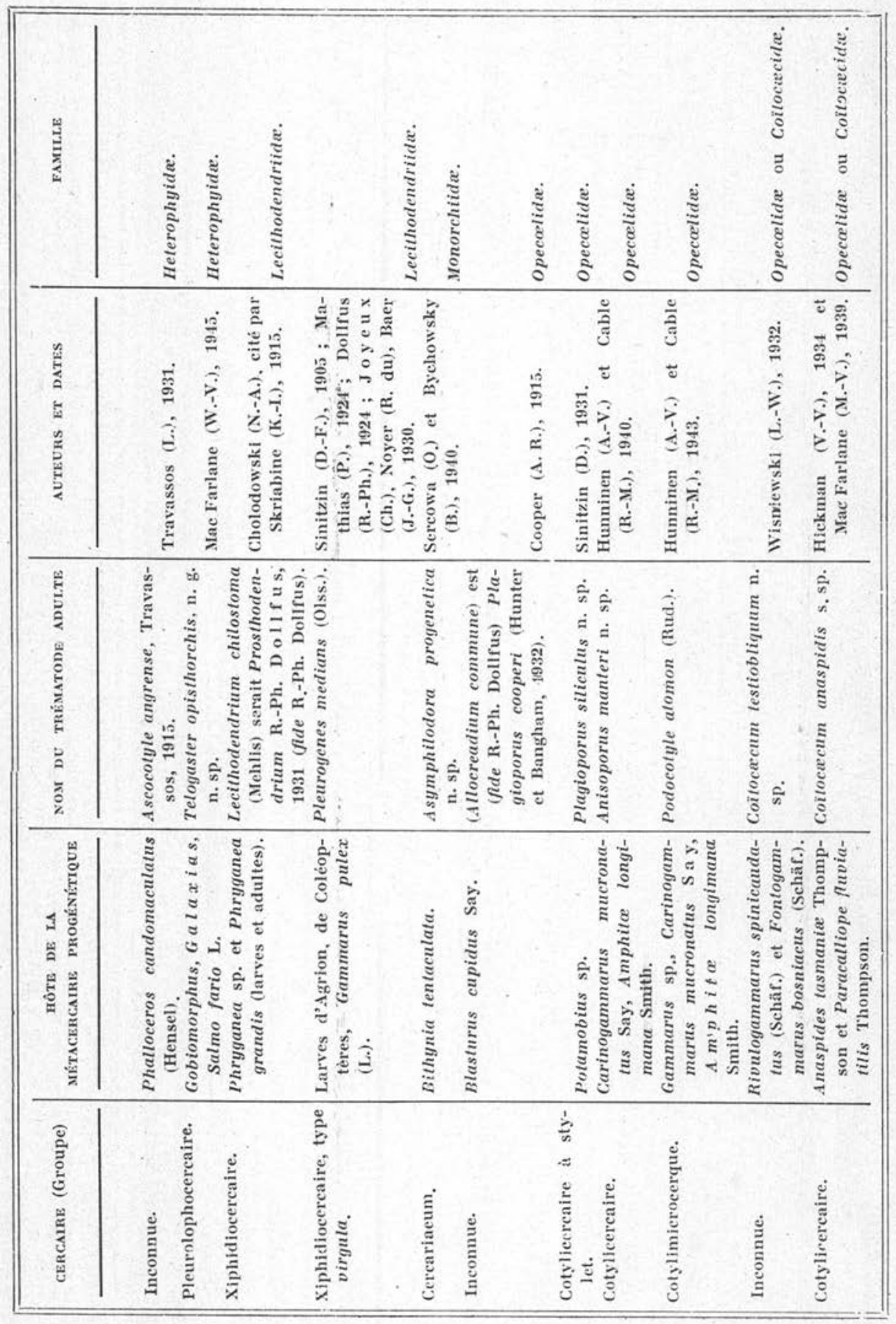




\begin{tabular}{|c|c|c|c|c|c|c|c|c|c|c|}
\hline 竞 & 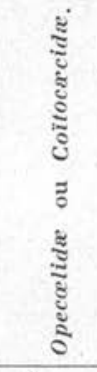 & 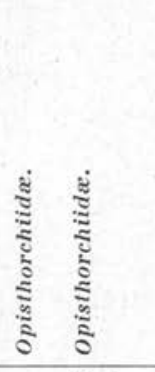 & 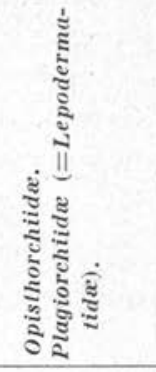 & 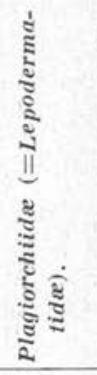 & 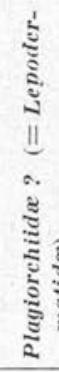 & 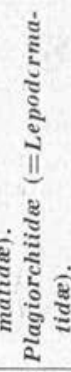 & 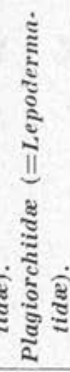 & & ڤั & 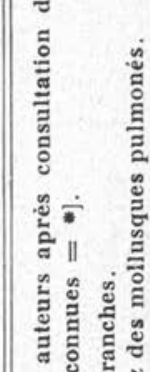 \\
\hline 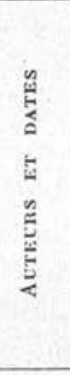 & 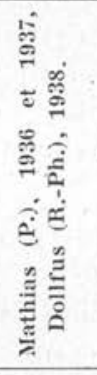 & 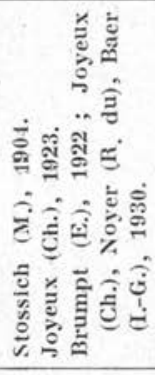 & 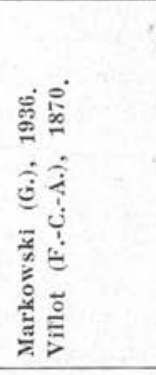 & 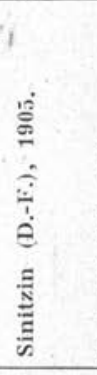 & 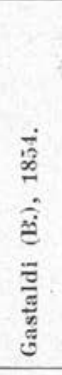 & 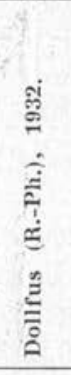 & 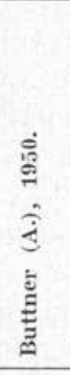 & & 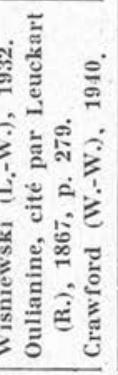 & 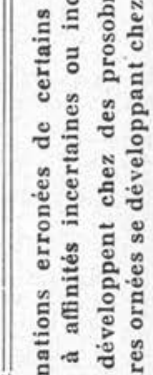 \\
\hline 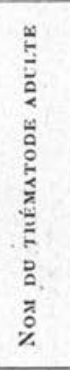 & 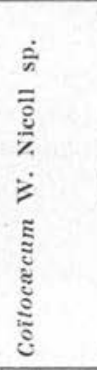 & 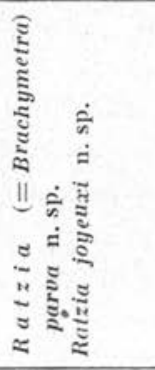 & 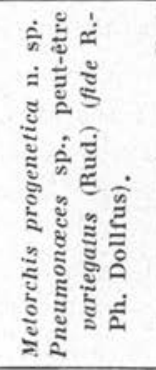 & 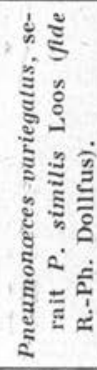 & 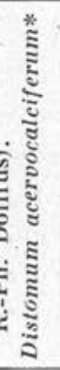 & 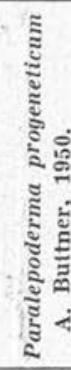 & 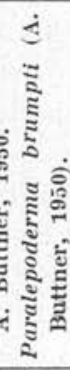 & 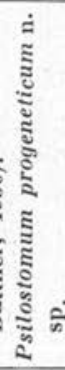 & 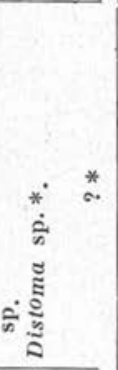 & 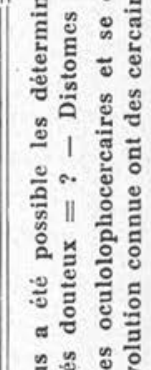 \\
\hline 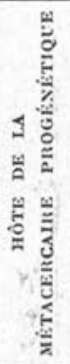 & 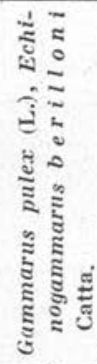 & 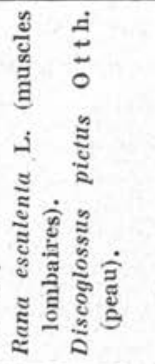 & 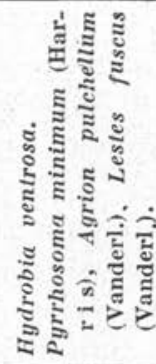 & 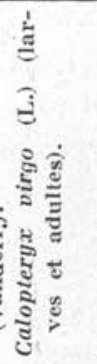 & 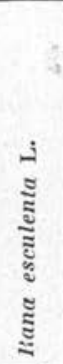 & 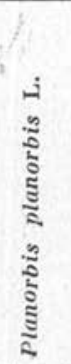 & 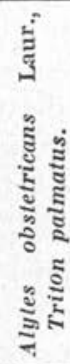 & 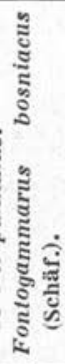 & 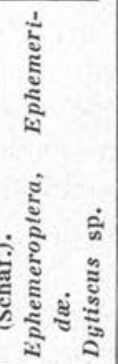 & 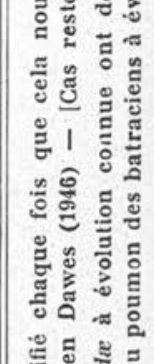 \\
\hline 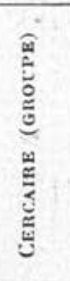 & 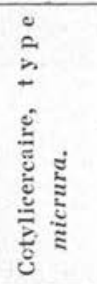 & 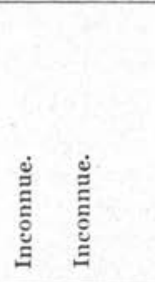 & 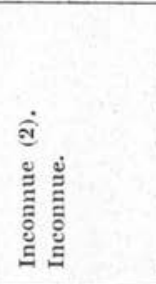 & $\begin{array}{l}\dot{\widehat{\vartheta}} \\
\stackrel{\Xi}{\Xi} \\
\stackrel{\Xi}{\Xi}\end{array}$ & $\begin{array}{l}\stackrel{\Xi}{\Xi} \\
\stackrel{\Xi}{\Xi}\end{array}$ & हूँ & 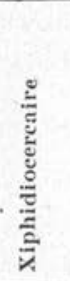 & $\begin{array}{l}\text { : } \\
\text { हूँ } \\
\text { 品 }\end{array}$ & 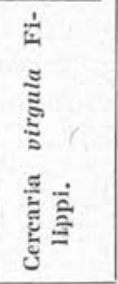 & 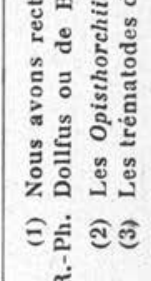 \\
\hline
\end{tabular}


Nous avons pu en étudier certains exemplaires sur coupes et préparations in toto (1). Nous donnons ci-après une étude des manifestitions déjà décrites de cet étrange phénomène.

\section{B. Cercaires progénétiques}

L'existence de cercaires progénétiques n'a été signalée qu'en Amérique du Nord, dans la famille des Azygiidx, vers dont l'évolution ne comporte pas de stade métacercaire : ce sont des cercaires cystocerques appartenant au groupe mirabilis de Sewell et naissant toujours dans des rédies.

Parmi les huit espèces de cystocercaires trouvées aux Etats-Unis, quatre ont été reconnues progénétiques ; pour les identifier, l'étude du fourreau caudal de la cercaire, celle du distome larvaire qu'il contient et la morphologie des palettes de la fourche terminale fournissent d'importants caractères taxonomiques.

Leur évolution s'effectue toujours chez des mollusques prosobranches. Les plus fréquemment parasités sont les Goniobasis ; dans une proportion moindre, les Pleurocera et les Campeloma servent également d'hôtes intermédiaires. Tous ces prosobranches ne se rencontrent qu'en Amérique du Nord.

La progénèse chez les cercaires pose les mêmes problèmes qu'au stade métacercaire : origine, déterminisme, possibilité d'un cycle abrégé (le distome larvaire est-il l'homologue d'un adulte ?). Les auteurs américains ne se sont guère préoccupés de cet aspect du problème, et s'il nous avait été possible, comme nous l'espérions, d'avoir en main du matériel vivant provenant des régions où ces parasites existent, nos efforts auraient précisément porté sur ce côté biologique de la question.

Il nous paraît néanmoins utile, en vue d'études ultérieures, de donner ici un exposé assez complet des cas de progénèse signales chez ces cercaires. Nous avons extrait des auteurs une étude précise du distome larvaire et de l'adulte, afin de pouvoir les comparer, et relaté tous les caractères biologiques qui nous ont paru susceptibles d'éclairer des recherches sur la progénèse chez ces espèces particulières d'Azygïdx.

Les cercaires cystocerques progénétiques actuellement décrites sont dues aux travaux de E. C. Faust (1918), H. S. Pratt (1919),

(1) C'est à Mrs. Margery Horsfall que nous devons la communication de ce précieux matériel, et nous lui exprimons ici nos vifs remerciements. 


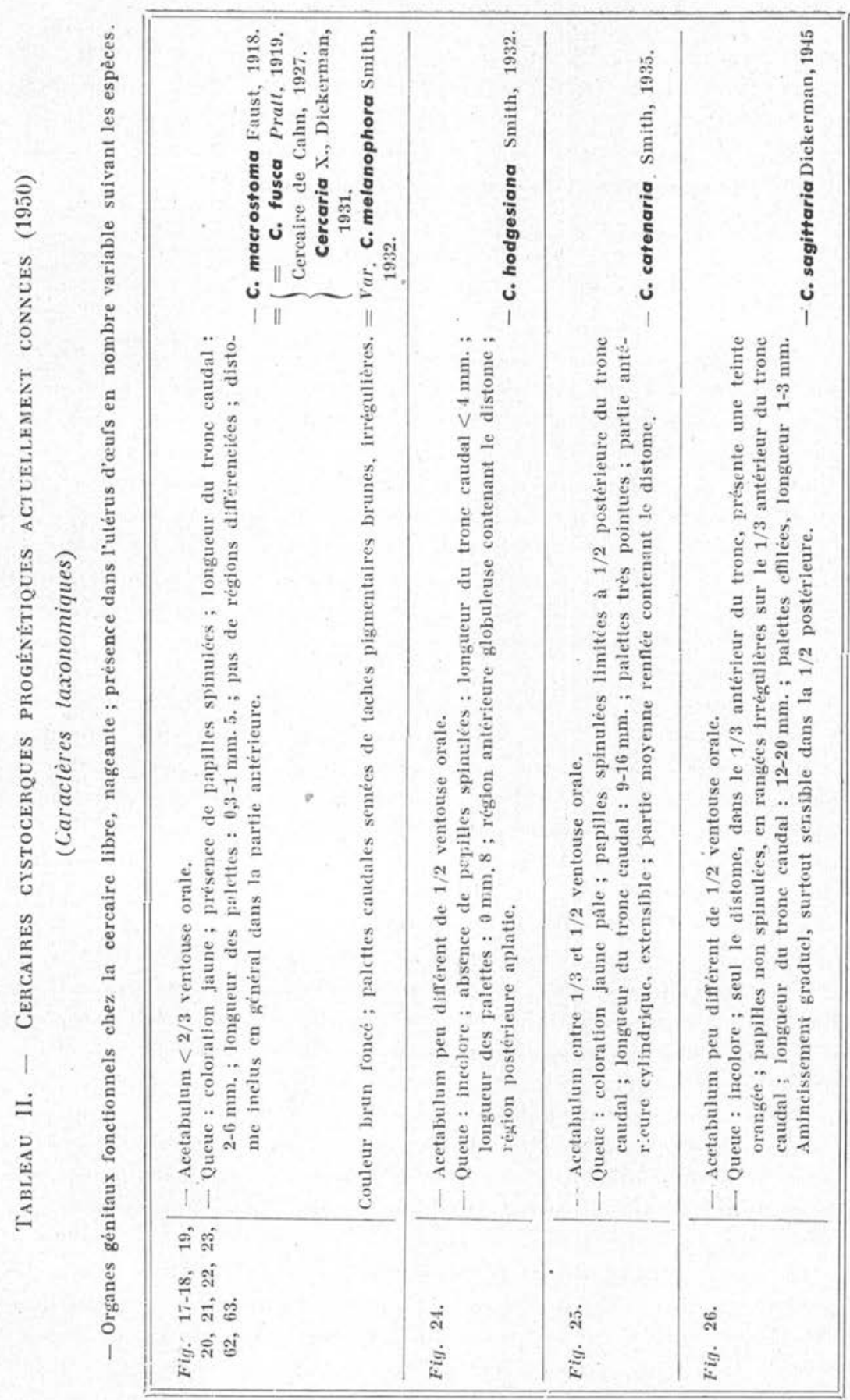


A. R. Cahn (1927), S. Smith (1932, 1934, 1935), M. W. Horsfall (1933, 1934), E. E. Dickerman $(1931,1934,1945,1946)$ et Ph. Seitner (1946).

Avant de les étudier, nous donnons ci-dessus un tableau taxonomique de ces différentes cercaires (tableau II).

\section{CERCARIA MACROSTOMA E. C. Faust, 1918}

La première cercaire progénétique qui ait été observée et décrite est celle de E. C. Faust, en 1918, qu'il a désignée sous le nom de Cercaria macrostoma n. sp. (fig. 17). Faust a isolé cette cercaire à partir d'un mollusque parasité, trouvé dans un aquarium d'eau douce au laboratoire de Zoologie de l'Université de l'Illinois. Il y avait dans cet aquarium des Goniobasis pulchella (Anthony) et des Campeloma solidum (Anthony), récoltés dans la région d'Homer Park (Illinois). Faust n'a pas précisé à quel genre appartenait le mollusque infesté. Il dit que la cercaire a des organes génitaux bien développés, constitués par deux testicules et un ovaire placés derrière la ventouse ventrale ; en avant de celle-ci, une vaste poche du cirre, à paroi cuticulaire épaisse, et, dorsalement, une grande vésicule séminale. L'utérus, rempli d'œufs mûrs, prend naissance dans la région de l'ovaire, s'enroule à quelque distance en arrière, contourne à droite l'acetabulum, se dirige en avant vers la zone du pharynx et, de là, vers le pore génital. Les œufs mesurent 78-88 $\mu$ de long et $47-50 \mu$ de large. Les follicules vitellins sont disposés en deux cordons s'étendant de chaque côté du corps, de la région pharyngienne à l'extrémité postérieure.

Depuis cette époque, la Cercaria macrostoma Faust 1918 a été décrite aux Etats-Unis sous plusieurs noms différents (voir tableau II) : ce fut d'abord la Cercaria fusca H. S. Pratt 1919, que Pratt découvrit chez des Goniobasis livescens (Menke) de l'Oneida River (New-York). D'après cet auteur, cette cercaire naissait dans des sporocytes ; mais il est probable, comme le suggère E. E. Dickerman, que ces pseudo-sporocystes étaient des rédies dont le pharynx et le tube digestif embryonnaire étaient en dégénérescence. Pratt mentionna la présence dans l'utérus d'œufs mesurant $78 \mu$ de long sur $49 \mu$ de large (fig. 18 et 19 ).

En 1927, A. R. Cahrr a retrouvé ces mêmes cercaires, sans les identifier, émergeant de Pleurocera acuta Rafinesque récoltés dans l'Oconomowoc River (Wisconsin). L'infestation de ce mollusque semble fréquente, puisque cet auteur signale un coefficient d'infes- 
tation de 96 p. 100 . Il observe jusqu'à 41 rédies chez un seul mollusque. Cahn obtint expérimentalement l'adulte chez des jeunes poissons de la famille des Centrarchidx.

E. E. Dickerman, en 1931, a, sous le nom de Cercaria X., étudié à nouveau cette cercaire chez des Goniobasis livescens correcta de la Des Plaines River (Hlinois) ; il a obtenu la forme adulte qu'il a identifiée plus tard à Proterometra macrostoma (Faust 1918).
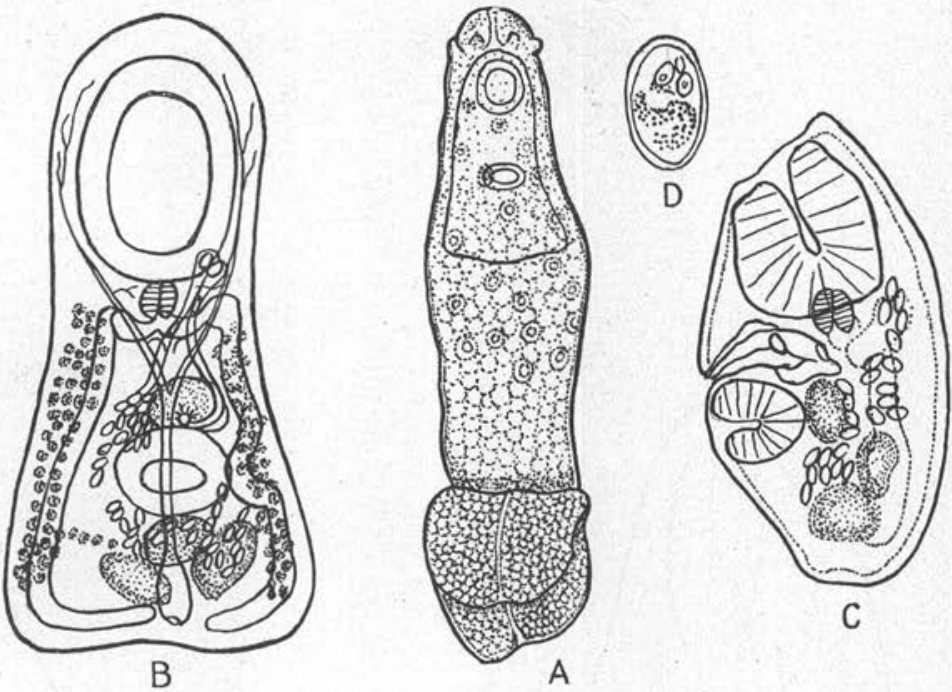

C

FIG. 17. - Cercaria macrostoma, Faust, 1918. A, cercaire in toto, face ventrale, $\times 14 ; B$, face ventrale de la douve vivante, $\times 54$; $C$, idem, profil, × 34 ; D, œuf utérin (d'après E. C. Faust, 1917-1918).

S. Smith (1932) donne, sous le nom de Cercaria melanophora, la description d'une cercaire trouvée chez des Goniobasis opaca (Anthony) de Cooley Creek, Jefferson County (Alabama). Sa longueur est d'environ 4,2 $\mathrm{mm}$. sur une largeur de $1,4 \mathrm{~mm}$. au niveau de la vésicule globuleuse contenant le distome (fig. 20). Celui-ci, de couleur brun foncé, mesure $1,6 \mathrm{~mm}$. sur $0,98 \mathrm{~mm}$.; il remplit à demi le sac ovoïde du trone caudal. Ce trone a une coloration diffuse brune et présente de nombreuses papilles spinulées. Les deux palettes terminales ont $1,12 \mathrm{~mm}$. sur $1,03 \mathrm{~mm}$. et sont semées de taches brunes irrégulières. L'adulte a été trouvé chez Huro floridana (Le Sueur) dans la même localité, ainsi que chez des poissons infestés expérimentalement, appartenant à la même espèce ou 
à d'autres espèces de la famille des Centrarchidæ. Le distome adulte ressemble étroitement, par sa morphologie et ses caractères essentiels, à Proterometra macrostoma (Faust 1918).

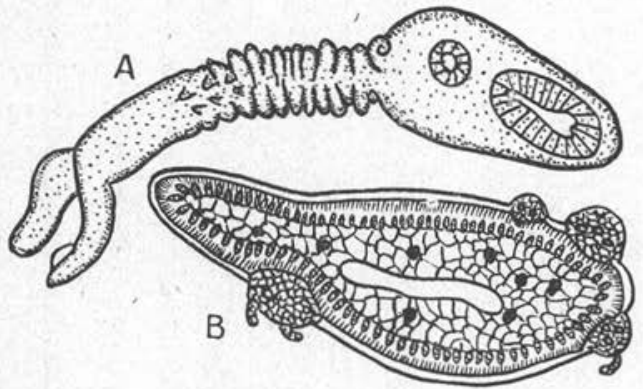

FIG. 18. - Cercaria fusca, Pratt, 1919. A, cercaire; $B$, coupe de la partıe antérieure de la queue, $\times 42$ (d'après H. S. Pratt, 1918-1919).
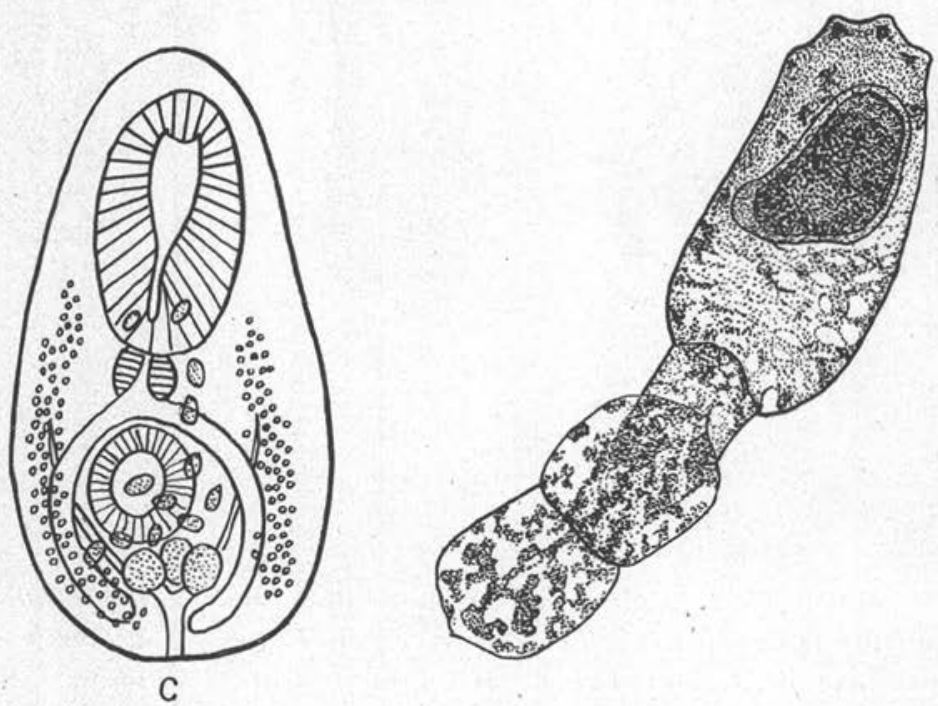

Fic. 19. - Cercaria fusca, distome extrait de l'appendice caudal (d'après H. S. Pratt, 1918$1919)$.

F1G. 20. - Cercaria melanophorc, Smith, 1932, $\times 19$ env. (d'après S. Smith, 1932)

Etudiant un important lot de Cercaria macrostoma provenant du Wisconsin, de l'Illinois, du Texas, de l'Alabama, de la Géorgie et de la Floride, S. Smith a pu noter de nombreuses variations de 

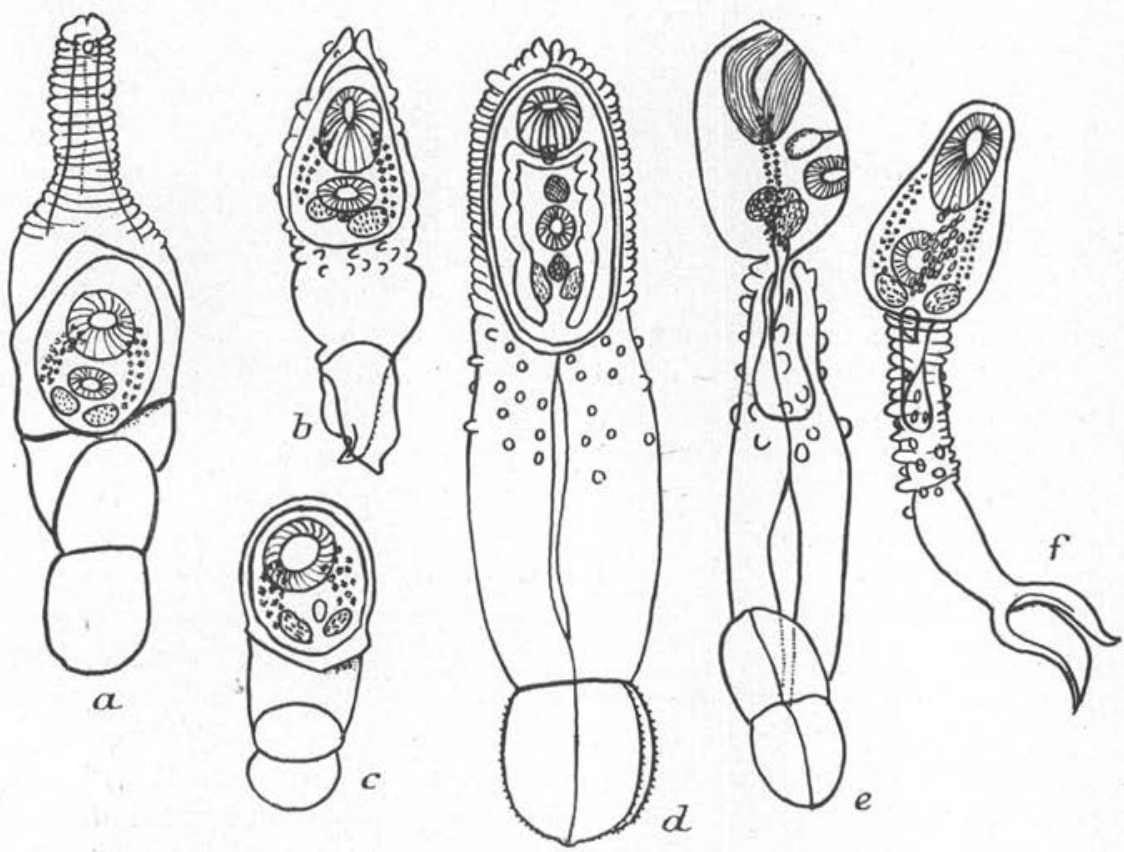

FIg. 21. - a, Cercaria macrostoma avec localisation anormale du distome ; $b$, idem, petite forme ; $c$, iden ; $d, C$. macrostoma ; e, forme immature de C. macrostoma; f, C. macrostoma progénétique (d'après M. W. Horsfall, 1934).

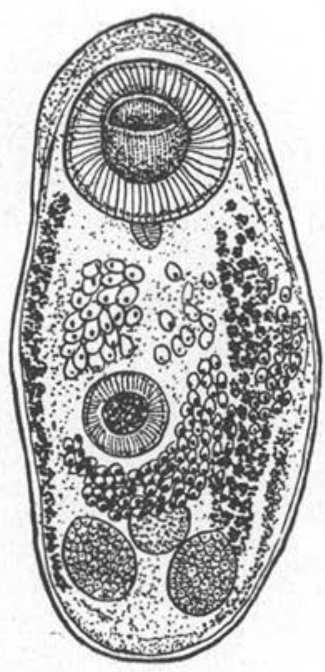

Fifs. 22. - Proteremetra macrostoma, Horsfall, 1934. Forme adulte montrant la croissance des oufs dans l'utérus, $\times 26$ env. (d'après une microphotographie de M. W. Horsfall, 1934). 
dimensions, de forme et de couleur parmi les exemplaires examinés ; cependant, pour une colonie donnée, ces variations restaient essentiellement constantes. Elles peuvent être vraisemblablement considérées comme des races géographiques de la cercaire de Faust, dont Cercaria melanophora serait un exemple particulièrement typique.

En 1933, Margery W. Horsfall, examinant des Cercaria macrostoma Faust 1918, provenant de Goniobasis livescens (Menke) de la Vermilion River et d'Homer Park (Illinois) (fig. 21), ainsi que de Pleurocera acuta Rafin. de l'Oconomowoc River (Wisconsin), les compara aux cercaires étudiées par E. C. Faust, H.S. Pratt et A. R. Cahn. Les spécimens envoyés par Cahn du Wisconsin étaient. légèrement plus petits que ceux récoltés à Homer, mais de structure et de proportions identiques. Elle estima que toutes ces cercaires ne formaient avec Cercaria macrostoma Faust qu'une seule et même espèce, à laquelle elle rapporta également Cercaria melanophora Smith 1932.

Chez tous les exemplaires ainsi étudiés, M. W. Hoŕsfall reconnut \& all adult structures including the genital organs which are functional ; the cirrus pouch contain active spermatozoa and the uterus from none to 50 eggs ». Elle obtint expérimentalement l'adulte, dont l'évolution avait été déjà réalisée chez plusieurs espèces de Centrarchidæ. Cet adulte fut désigné par elle sous le nom de Proterometra macrostoma (E. C. Faust 1918) M. W. Horsfall 1933, comme type d'un nouveau genre d'Azygiidx.

Quelques mois plus tard (1934), parut le travail d'E. E. Dickerman sur la morphologie et le cycle évolutif de Proterometra macrostoma Horsfall. L'auteur signale brièvement les nourrices (sporocystes et rédies) chez lesquelles se développent les cercaires. En ce qui concerne leur évacuation, il n'a jamais observé d'émission par l'anus du mollusque comme l'admet Cahn (1927), ni que des rédies aient été trouvées dans le foie des mollusques (Pratt, 1919; Horsfall, 1933).

Les cercaires sont émises en général quatre jours après la récolte des mollusques, entre 19 et 24 heures. Quand les mollusques parasités sont disséqués, le distome, au lieu d'être inclus dans le tronc caudal de la cercaire, se trouve placé à son extrémité antérieure et ce n'est qu'ultérieurement qu'il s'invagine à l'intérieur, ainsi qu'on peut l'observer chez toutes les cercaires émises spontanément. L'auteur admet donc que les descriptions de Cercaria macrostoma Faust, données antérieurement, présentant le distome à l'extrémité antérieure, sont en réalité celles de cercaires immatures, obtenues par dissection des mollusques parasités. 
Signalons encore des détails intéressants sur la biologie de cette cercaire : elle est jaune, assez grande pour être perçue sans le secours d'une loupe ; 10 ou 12 heures après son émission, c'est-àdire vers la fin de la matinée, on peut la contraindre à nager en créant un fort courant d'eau ; à partir de 14 heures, elle refuse de se mouvoir, et cependant le distome continue à donner des signes de vie pendant environ trois jours.

Action de la température: Les cercaires furent conservées pendant trois jours à une température voisine de $0^{\circ}$; les mouvements de natation cessèrent; mais, remises dans l'eau à la température ambiante, elles reprirent aussitôt leurs mouvements et recommencèrent à nager.

Il est impossible, quelle que soit la pression exercée, de faire sortir le distome de la chambre dans laquelle il se trouve, bien qu'il existe à l'extrémité antérieure un orifice par lequel le trématode est entré. Mais le sac peut être ouvert avec des aiguilles et l'animal isolé. Horsfall a signalé, en 1933, qu'une solution de $\mathrm{ClH}$ à 1/1.000 permettait la libération du ver.

Le distome de la cercaire et l'adulte ne présentent pas de différences morphologiques, sinon en ce qui concerne les dimensions, légèrement supérieures chez l'adulte, et le nombre d'œufs présents dans l'utérus (1).

Infestations expérimentales : Pendant l'été 1931, un certain nombre d'expériences d'infestation furent tentées sur des grenouilles et différents poissons. Les résultats positifs ont été obtenus avec des Helioperca incisor.

E. E. Dickerman a été moins heureux que M. W. Horsfall dans ses expériences, car, chez 10 poissons exposés à un total de 436 cercaires, il n'a obtenu en tout que 51 vers adultes. M. Horsfall avait utilisé d'autres espèces de Centrarchidæ (Allotis humilis, Huro floridana) ; en particulier, 10 exemplaires d'Allotis, provenant d'une région où ces poissons n'étaient pas infestés par Proterometra, ingérèrent sous ces yeux cinq cercaires chacun; sacrifiés 15 jours plus tard, ils montrèrent dans leur œsophage et leur estomac quatrecinq exemplaires adultes, alors que vingt témoins de même origine étaient négatifs. En ce qui concerne les Huro floridana, vingt exemplaires furent utilisés : trois furent autopsiés immédiatement, trois autres 10 jours plus tard; ils présentaient uniquement quelques exemplaires de Cæcincola parvulus; sept poissons furent nourris

(1) Dans une lettre récente (avril 1950), Mrs. Horsfall nous a précisé que les œufs de cercaires progénétiques qu'elle avait examinés ne présentaient jamais de miracidium formé. 
sous les yeux de l'auteur avec six Cercaria macrostoma chacun, sept autres furent conservés comme témoins. Vingt jours plus tard, les Huro ayant ingéré des cercaires présentaient chacun cinq ou six Proterometra adultes, alors que les-sept témoins n'en hébergeaient aucun.

La diversité des résultats expérimentaux obtenus par Dickerman et Horsfall tient peut-être à la différence d'espèces des poissons utilisés par ces deux auteurs.

La liste des poissons hébergeant spontanément $P$. macrostoma dans leur tube digestif est la suivante ; ils appartiennent tous à la famille des Centrarchidæ:

Pomoxis sparoides (black crappie), P. annularis (white crappie), Ambloplites rupestris (rock bass), Eupomotis gibbosus, Chænobryttus gulosus. Apomotis cyanellus, Allotis humilis, Helioperca incisor, Huro floridana, Micropterus dolomieu (small-mouthed black bass), Aplites (Micropterus) salmoides (large mouthed black bass).

L'adulte, Proterometra macrostoma, est petit, qu'il ait été trouvé expérimentalement ou spontanément chez des poissons infestés; il mesure seulement $3 \mathrm{~mm}$. de long quand il est vivant et en pleine extension. Tué par les procédés habituels et légèrement aplati, il n'a plus que $1,8 \mathrm{~mm}$. à $2,1 \mathrm{~mm}$. de long sur $1 \mathrm{~mm}$. à $1,2 \mathrm{~mm}$. de large. Sa coloration est brun clair et le contenu fluide des cæcums intestinaux y marque une traînée rose. Nous n'entrerons pas dans la description morphologique de l'adulte, dont Dickerman donne une diagnose très complète; signalons simplement la présence d'un canal de Laurer bien développé. La glande de Mehlis forme une masse assez importante. Les spermatozoïdes sont abondants. La fécondation se fait-elle par l'orifice utérin ou par le canal de Laurer ? C'est ce qui n'a pu être établi pour cette espèce de Trématode.

Toutefois, l'ovogénèse et la spermatogénèse ont été étudiées chez la cercaire par M. G. Anderson, en 1935, sur du matériel provenant de Goniobasis livescens (Menke) récoltés dans la Des Plaines River (Illinois). En 1936, F. Bryant reprit cette étude sur du matériel provenant de Goniobasis carinocosta (Say), mollusques que S. Smith avait trouvés dans le Coosa River drainage (Alabama). Sur des coupes sériées, colorées à l'hæmatoxyline ferrique ou par la méthode de Feulgen, Bryant a pu dénombrer le chiffre diploïde de chromosomes qui est de 18 . Il a observé les différents stades de la spermatogénèse, spermatogonies, spermatocytes, spermatides et spermatozoïdes, qui sont formés en rouleaux serrés et graduellement évacués à la maturité. L'ovogénèse est d'une observation plus difficile en raison des nombreuses cellules nourricières existant dans l'ovaire. Cependant, Bryant a pu voir les oogonies entrant dans la 
phase d'accroissement, qui se poursuit pendant la prophase de la première division de maturation. L'ovocyte de premier ordre passe dans l'ootype pendant la métaphase, et c'est à ce moment que le spermatozoîde pénètre dans l'œuf et que la coque se constitue. L'étude des stades ultérieurs est rendue malaisée par l'épaisseur de la coque qui se coupe mal. Cependant, les deux pronuclei ont été observés, ainsi que la métaphase de la mitose réductionnelle.

Dickerman donne sur la présence d'œufs chez l'adulte les renseignements suivants : le vagin et l'utérus peuvent être remplis par des œufs dont le nombre atteint parfois $300 \mathrm{chez}$ les grands exemplaires. Le vagin diffère de l'utérus par la présence d'une fine cuticule. L'œuf est ovale et nettement operculé. Les mensurations d'œufs de plusieurs spécimens donnent des dimensions moyennes de $82 \mu$ sur $49 \mu$. Les mesures maxima ont été de $86 \mu \times 57 \mu$ et les minima de $70 \mu \times 37 \mu$.

M. W. Horsfall avait affirmé (1933) que les œufs s'accroissaient de 65 à $95 \mu$ en longueur et de 34 à $75 \mu$ en largeur durant leur transit dans l'utérus, ce qui semblerait établir que les œufs grandissent dans le corps du distome. Dickerman, lui, n'a pas observé cet accroissement; les œufs des plus petits spécimens, au voisinage de la glande coquillère, avaient leurs dimensions habituelles de $82 \mu \times 49 \mu$; ceux prêts à être pondus avaient la même taille; ils renfermaient un miracidium non cilié présentant quatre plaques antérieures ciliées.

Dans un travail ultérieur (1934), M. W. Horsfall fait état d'une microphotographie (fig. 22) montrant le changement de forme et de dimensions des œufs pendant leur développement. "Cette croissance intra-utérine, dit-elle, est un trait caractéristique de ce distome, facile à observer sur les exemplaires vivants. Dès que la coquille est formée, l'œuf a une apparence particulière, une seule cellule claire se trouvant près du pôle operculaire, tandis que la masse sombre du matériel vitellin est concentrée au pôle opposé. A ce moment, l’ouf a une apparence blanche et noire très frappante ; au fur et à mesure de son développement, la cellule unique se divise et grossit jusqu'à remplir la presque totalité de la coquille, tandis que le matériel vitellin n'est plus représenté que par quelques granulations disséminées à la périphérie. »

M. W. Horsfall donne ensuite les renseignements suivants sur l'évolution de l'œuf : "La coque brunit, prend une coloration jaune foncé et de longs filaments incolores recouvrent sa surface. Ces filaments paraissent gluants et permettent à l'œuf d'adhérer aux objets qui s'offrent à lui, mais ils sont fragiles et disparaissent peu après l'expulsion des œufs. Ces filaments 
ne sont visibles que dans certaines conditions d'éclairement et dans des œufs récemment évacués. A ce moment, le miracidium commence à bouger à l'intérieur de la coque et sa structure devient discernable. Une sécrétion granuleuse noire couvre le tiers antérieur de l'organisme. Deux canaux partent de cette région et vont s'ouvrir au-dessous de la zone où se réunissent les quatre plaques antérieures ciliées. De chacune de ces plaques, part une ligne fine de petites soies qui s'étend jusqu'à la partie postérieure du miracidium. Une seule flamme vibratile a été observée près de l'extrémité postérieure du miracidium. Les miracidiums n'ont jamais été vus sortant de leur coque, bien qu'ils se lancent énergiquement contre la paroi ; ils continuent à vivre pendant plusieurs semaines dans l'eau ordinaire. Quand l'opercule est arraché, ils cessent de bouger et dégénèrent rapidement. »

Toutes les tentatives effectuées pour infester des mollusques, en les mettant au contact des œufs éliminés par le distome adulte, ont été infructueuses. Cet échec n'est peut-être pas définitif et il est possible que la température de l'eau, la durée de séjour des mollusques avec les œufs, un contact plus ou moins étroit, ou encore l'ingestion des œufs par les mollusques soient autant de facteurs qui jouent, à l'insu de l'expérimentateur, dans le déterminisme de l'éclosion de l'œuf.

M. W. Horsfall a remarqué fréquemment des œufs anormaux, semblant ne contenir que du matériel vitellin. Expulsés en même lemps que les œufs normaux, ils s'en distinguent par leur petite taille et leur contenu flétri. La cellule œuf est-elle absente ou simplement dégénérée ? La question n'a pu être résolue.

Observons que cette croissance caractéristique des œufs dans l'utérus semble fréquente dans le genre Proterometra, et les microphotos données par S. Smith de $P$. catenaria et surtout $P$. hodgesiana (fig. 25, $b$ et 24, c) la font apparaitre nettement. Nous avons relevé dans le travail de Ben Dawes (The Trematoda) les cas suivants de distomes appartenant à des familles très différentes et présentant cette particularité :

$1^{\circ}$ Diphterostomum brusinæ (Stossich) 1889 (Zoogonidæ) : Les œufs augmentent de taille dans l'utérus et passent de $43-46 \mu \times$ $28 \mu$ à $57 \mu \times 23 \mu$. Chacun contient un embryon vivant.

$2^{\circ}$ Zoogonus vividus Nicoll 1913 (Zoogonidæ): Les œufs sont relativement petits, à coque mince, augmentent de taille pendant leur passage à travers l'utérus, de $16 \mu \times 12 \mu$ à $36 \mu \times 18 \mu$.

$3^{\circ}$ Derogenes varicus (Müller) 1784 (Hemiuridæ) : Cufs jaune doré de $50-62 \mu \times 25-34 \mu$ (parfois plus grands, jusqu'à $60 \mu \times$ 
$38 \mu$ ) ; les plus grands se trouvent toujours dans la partie de l'utérus en avant de la ventouse ventrale.

$4^{\circ}$ Phyllodistomum macrocotyle (Lühe) 1909 (Gorgoderidæ) : Eufs s'accroissant pendant leur passage dans l'utérus de $32 \mu \times$ $18 u$ à $54 \mu \times 36 \mu$.

$5^{\circ}$ Gorgodera cygnoides (Zeder) 1800 (Gorgoderidx) : CEufs mesurant environ $31 \mu \times 16 \mu$ peu après avoir quitté l'ootype, deviennent beaucoup plus grands dans l'utérus et atteignent $47-48 \mu \times$ 30-31 н.

$6^{\circ}$ Parorchis acanthus (Nicoll) 1906 (Echinostomatidx) : CEufs s'accroissant en dimensions dans l'utérus de $80 \mu \times 44 \mu$ à $100 \mu \times$ 60 u.

Signalons encore un cas particulier de la croissance des œufs jusqu'à la maturité, non plus dans l'utérus, mais après la ponte, au cours des migrations dans les tissus, pour les œufs de schistosomes.

En 1934, M. W. Horsfall fit paraître l'importante mise au point de toutes les cercaires cystocerques appartenant au groupe mirabilis de Sewell. Au cours de ce travail, l'auteur donne une description très précise du cycle évolutif de $C$. macrostoma, grâce à un abondant matériel vivant, mais n'a pu réussir à obtenir l'infestation des prosobranches, premiers hôtes intermédiaires. Les mollusques étaient placés dans des aquariums bien aérés, contenant des pierres et des plantes vivantes. Les cercaires émises, de grande taille, étaient aisément repérables dans l'eau claire. Les mollusques parasités, isolés pendant deux semaines, étaient ensuite réunis dans le même aquarium, et vivaient là pendant plusieurs mois, fournissant constamment des cercaires pour les études morphologiques et les infestations expérimentales. Les cercaires et les adultes étaient fixés dans une solution de sublimé de Gilson ou dans du picroformol de Bouin (signalons au passage que l'alcool-formol est meilleur pour les préparations in toto).

Les dimensions données par Horsfall pour des cercaires émanant de Goniobasis livescens récoltés à Homer Park sont les suivantes : tronc caudal : $2-6 \mathrm{~mm}$. $\times 0,59-1,7 \mathrm{~mm}$. ; palettes : 0,29-1,5 mm. $\times$ $0,5-1,58 \mathrm{~mm}$. ; distome : 0,67-3,5 mm. $\times 0,35-1,45 \mathrm{~mm}$.

Chez tous les spécimens examinés, les proportions et l'organisation étaient identiques, bien que les dimensions et l'état de développement soient parfois variables (fig. 21, $a-f$ ). Ces dimensions semblaient varier à l'inverse de la longévité des mollusques parasités au laboratoire. Ces variations peuvent, dans une certaine mesure, rendre compte des dimensions différentes données pour 
cette espèce par les auteurs. Les formes de C. macrostoma du Wisconsin étaient plus petites et moins bien développées sexuellement que celles trouvées en Alabama. C'est pourquoi, dit Horsfall, l'étude comparée de quelques spécimens et de matériel provenant d'une localité déterminée ne peut donner qu'une conception incomplète de ce qu'est en réalité $C$. macrostoma.

Chez le mollusque, M. W. Horsfall, comme E. E. Dickerman, observe d'abord un petit sporocyste qui ne possède ni intestin, ni pharynx, dans lequel se développent des rédies, puis de petites rédies avec un intestin visible et un pharynx ne contenant que des masses germinatives ; enfin, de grandes rédies n'ayant plus d'intestin et dont le pharynx est dégénéré, chez lesquelles les cercaires se développent D'où le schéma de l'évolution probable chez le mollusque : miracidium, sporocyste, petite rédie, grande rédie portant les cercaires.

La rédie mûre est allongée, de couleur jaune et mesure de 0,75 à $8 \mathrm{~mm}$. de long sur 0,5 à $1 \mathrm{~mm}$. de large. Les mensurations moyennes de 10 rédies vivantes étaient $2,92 \mathrm{~mm}$. $\times 0,76 \mathrm{~mm}$. Extraites du mollusque, elles peuvent s'allonger et doubler de longueur; au bout de quelques heures, les mouvements cessent, mais les rédies continuent à changer de forme par pression des cercaires qu'elles renferment (1).

En règle générale, une rédie mûre contient une seule cercaire prête à sortir et possédant des organes génitaux fonctionnels; il y a en outre deux à quatre cercaires en partie différenciées et cinq à huit masses germinatives. Les cercaires rampent les unes au-dessus des autres avec leur large ventouse orale, mais l'auteur dit ne les avoir jamais vu manger les petites formes immatures, comme cela a été signalé dans certaines familles par Wesenberg-Lund (cannibalisme des rédies, les plus âgées mangeant les plus jeunes, 1934, p. 195).

M. W. Horsfall constate que les rédies présentent un petit orifice au niveau où se trouve le pharynx dégénéré, mais cet auteur ne peut affirmer qu'il représente l'orifice d'où s'échappent les cercaires ; en revanche, Mrs. Horsfall a aperçu une fois une cercaire perforer la paroi cuticulaire de la rédie avec sa ventouse orale et se libérer ainsi. Dans certains cas, des cercaires trop jeunes pour être évacuées ont été trouvées libres dans les tissus du mollusque; ce fait a été déjà observé chez tous les Amphistomes et certains Monostomes.

(1) Nous donnons plus loin une étude et des figures originales (fig. 62 et 63) de rédie et de cercaires progénétiques de cette espèce, travail que nous avons pu effectuer grâce au matériel scientifique que Mrs. M. W. Horsfall nous a obligeamment communique. 
Le pourcentage d'infestation des mollusques de la région de Homer Park constaté par Horsfall est faible (6 p. 100). Le plus haut coefficient a été observé en juin et juillet. Le degré d'infestation varie donc avec le lieu et la saison, et l'espèce du mollusque parasitée.

Chez les poissons infestés expérimentalement, le distome adulte, Proterometra macrostoma, se trouve le plus souvent fixé à l'œsophage, immédiatement au-dessous des dents pharyngiennes; occasionnellement, il émigre dans la bouche ou dans l'estomac. Quand le poisson meurt, les vers se répandent partout, même à la face externe du corps. C'est environ 30 jours après l'infestation que les Proterometra macrostoma émettent des œufs mûrs pourvus d'un miracidium mobile. Toutefois, quand les cercaires sont progénétiques et renferment de 25 à 50 œufs, la maturité du distome se fait en 15 jours environ. D'après cette observation, il semble que les cercaires émises ne soient pas toujours progénétiques. Cependant, dans aucun des travaux précédemment cités, il n'a été fait mention d'un pourcentage de ces cercaires progénétiques vis-à-vis des autres cercaires lors de leurs émissions ; il est au contraire d'autres indications qui sembleraient impliquer pour ces cercaires une progénèse obligatoire, témoin la phrase citée plus haut dans laquelle il est dit que la rédie mùre ne contient qu'une cercaire prête à éclore et qui porte des organes génitaux fonctionnels.

Comme Dickerman, Horsfall trouve chez l'adulte une structure identique, mais une taille légèrement supérieure à celle du distome larvaire; elle ajoute que le nombre d'œufs du ver adulte masque certaines structures très visibles chez la larve. Les dimensions moyennes du distome adulte vivant sont, en extension, $3,11 \mathrm{~mm}$. $X$ $0,87 \mathrm{~mm}$. ; en contraction, $2,28 \mathrm{~mm}$. $\times 1,38 \mathrm{~mm}$. Extrait de son hôte définitif, $P$. macrostoma peut vivre de 6 à 10 heures dans l'eau ordinaire et beaucoup plus longtemps à une température plus basse.

Cette étude sur Cercaria macrostoma ne serait pas complète si nous ne citions encore le travail de Dickerman en 1945, qui apporte des éléments nouveaux à l'étude de sa biologie. L'auteur a récolté, dans plusieurs localités de la région des grands lacs, plus de 500 prosobranches (Goniobasis et Pleurocera) infestés par Cercaria macrostoma. L'étude à frais ou sur coupes de cet important matériel lui a permis de reconstituer avec le plus de vraisemblance possible le cycle évolutif complet de Proterometra macrostoma. Voici comment il l'imagine :

« Le miracidium non cilié reste dans la coquille de l'œuf jusqu'à ce que ce dernier ait été ingéré par un mollusque d'eau douce, Goriobasis ou Pleurocera. Dans l'intestin du mollusque, le mira- 
cidium sort par ouverture de l'opercule de l'œuf, et, à l'aide de ses quatre plaques ciliées, il émigre dans la paroi intestinale où il se développe en un sporocyste primaire. Celui-ci grandit, passe dans le colome et donne naissance à 10-20 rédies; à leur tour, ces rédies augmentent de taille et de nombre et, occasionnellement, elles provoquent la rupture de la paroi située entre la cavité du corps et la chambre palléale du mollusque, permettant ainsi la mise en liberté dans le milieu extérieur, à travers la chambre palléale, de la cercaire mûre. Le cycle est complet quand la cercaire est ingérée par un hôte favorable. »

Dickerman a vu des sporocystes pour la première fois pendant l'automne 1933, époque à laquelle il en a observé trois qu'il a étudiés. Le premier provenait d'un mollusque disséqué par Anderson qui lui avait communiqué les coupes. Les deux autres étaient très petits et ont été trouvés ensemble dans la cavité généralé d'un mollusque disséqué. Durant l'été et l'automne 1934, 2.264 Goniobasis, originaires de la Des Plaines River, à l'ouest d'Evanstone (Illinois), furent soigneusement examinés. Sur 227 mollusques infestés, 26 sporocystes seulement furent récoltés ; chez un mollusque, il fut trouvé 4 sporocystes et 788 rédies. Au cours de l'été 1935,16 sporocystes furent obtenus de 85 Goniobasis infestés du lac Erié, ce qui porte à 45 le total des sporocystes étudiés par l'auteur ; ce dernier signale leurs dimensions très variables, le plus grand mesurant $3 \mathrm{~mm}$. de long sur $1 \mathrm{~mm}$. de large (1).

Les sporocystes sont incolores, mais ils deviennent jaune foncé quand ils portent des rédies, contrastant avec la légère pigmentation jaune citron des rédies libres. La couleur foncée des sporocystes est certainement due à leur âge avancé, car ils avaient l'aspect ratatiné et contenaient un petit nombre de jeunes rédies, mais plus de germes.

Des centaines de rédies ont été étudiées par Dickerman ; à l'état adulte, elles sont fusiformes et peuvent atteindre une longueur de plus de $8 \mathrm{~mm}$. Un total de 1.270 rédies, mesurées après avoir été fixées au Bouin, offraient une longueur constante de 2,5 mm. et une Jargeur de $0,7 \mathrm{~mm}$. Les plus petites possédaient un intestin et un pharynx, mais, en grandissant, l'intestin disparaissait peu à peu et le pharynx, circonscrit par un petit nombre de fibres musculaires et longitudinales, devenait l'orifice de ponte.

Les rédies donnent naissance aux cercaires, qui sont mises en

(1) Cette grande dimension des sporocystes nous paraît un peu insolite chez un trématode digénétique dont les cercaires évoluent chez des rédies. Le miracidium donne en général des sporocystes petits où se développent les rédies mères. 
liberté par la rupture de la paroi de la cavité du corps et sortent par la chambre du manteau.

Dịckerman signale ce fait particulièrement intéressant: l'apparition de trois types différents de Cercaria macrostoma chez des

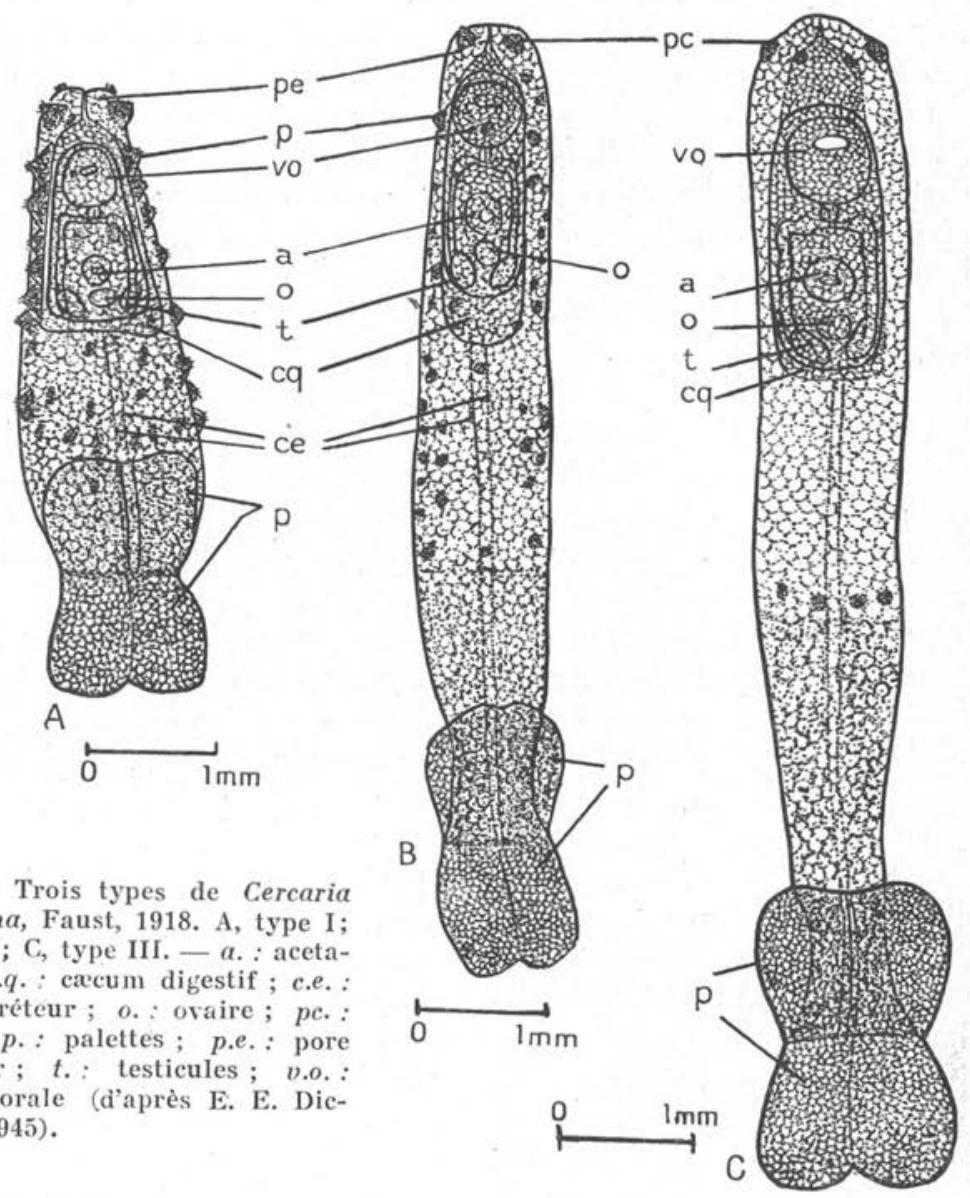

FIG. 23. - Trois types de Cercaria macrostoma, Faust, 1918. A, type I; B, type II ; C, type III. - a. : acetabulum ; c.q. : cacum digestif ; c.e. : canal excréteur ; o. : ovaire ; pc. : papille ; p.: palettes; p.e.: pore évacuateur ; $t$. : testicules ; v.o. : ventouse orale (d'après E. E. Dickerman, 1945).

Goniobasis de la région de Bass Island, à l'ouest du lac Erié, durant l'été de 1935.

Le type 1 (fig. 23, A) présentait un pigment jaune canari foncé ; sa longueur moyenne était de $4 \mathrm{~mm}$. Les deux tiers antérieurs du tronc caudal étaient semés de larves verrues ou papilles, recouvertes par de grandes épines acérées. Le distome dans la cavité du tronc était bien développé et contenait 30 à 50 œufs. 
Le type 2 (fig. 23, B), d'une pigmentation jaune pâle, avait de 6 à $8 \mathrm{~mm}$. de long; les deux tiers antérieurs du corps étaient couverts de petites papilles présentant quelques rares épines pointues. Le distome dans la cavité du tronc caudal était mûr, mais ne produisait pas d'œufs.

Le type 3 (fig. 23, C) était une grande forme non pigmentée de 7 à $9 \mathrm{~mm}$. de long. Les deux tiers antérieurs du tronc caudal étaient presqu'entièrement lisses; une rangée de verrues était disposée à la partie antérieure et une autre rangée entourait la partie postérieure, un peu au-dessous de la moitié antérieure du tronc. Le distome dans sa cavité, bien que parfaitement développé, ne contenait jamais d'œufs.

Ces trois types restaient constants et aucune forme de passage n'a été observée.

Dickerman crut qu'il s'agissait de trois espèces différentes; il les fit ingérer séparément à trois lots de poissons de l'espèce Aplites salmoides (large mouth black bass) et, à sa grande surprise, il obtint chez ces animaux des distomes adultes qu'il fut impossible de distinguer morphologiquement les uns des autres, sinon en ce qui concerne de très légères variations de taille.

L'auteur obtint ainsi 22 Proterometra du type 1, 21 du type 2 et 58 du type 3 . Le nombre moyen d'œufs par ver était de 113 dans le type 1 , de 21 dans le type 2 et de 37 dans le type 3.

De nombreux œufs furent mensurés : 85 du type 1, 77 du type 2, 259 du type 3 . La moyenne fut de $70 \mu \times 40 \mu$ pour le type $1,70 \mu \times$ $41 \mu$ pour le type 2 , et $72 \mu \times 40 \mu$ pour le type 3 .

Nous pensons qu'il eût été intéressant de savoir si les œufs mûrs émanant des types 1,2 et 3 , mis au contact de mollusques neufs de la même espèce, auraient redonné les cercaires des trois types. Signalons, en effet, que l'auteur ne dit pas dans son travail chez quelles espèces de prosobranches il a trouvé ces trois cercaires; il ne mentionne que le nom générique, Goniobasis. Or, d'après Ward et Whipple, il existait en 1918 un très grand nombre d'espèces de Goniobasis, puisque ce genre comprend les $3 / 5$ des espèces de la famille des Pleuroceratidæx, elle-même constituée par de nombreux genres comportant un certain nombre d'espèces. Il est donc possible que la spécificité des miracidiums pour certaines espèces de Goniobasis rende compte des différences morphologiques des trois types de Cercaria macrostoma observés par Dickerman.

Signalons enfin, pour terminer, que Ph. G. Seitner (1946) a trouvé chez Pleurocera acuta et Goniobasis livescens, probablement dans l'Indiana, une cercaire qu'il identifie avec quelque doute à $C$. macrostoma, car elle présente une longueur de $19 \mathrm{~mm}$. et se rappro- 
cherait plutôt par sa taille de $C$. sagittaria Dickerman (1945). Les hôtes définitifs sont différents poissons infestés expérimentalement.

Diagnose de Proterometra machostoma (E. C. Faust 1918)

1. Morphologie: dimensions moyennes:

Adulte: $2-3 \mathrm{~mm} . \times 1-1 \mathrm{~mm} .3$; nombreux œufs dans l'utérus (env. 300), grandissent en mûrisant ; œufs mûrs : $82 \mu \times 49 \mu$ (moyenne).

Cercaire: papilles spinulées; tronc caudal : $2-6 \mathrm{~mm} .8 \times 0,59-$ $1 \mathrm{~mm} .7$; palettes terminales : $0,29-0 \mathrm{~mm} .5 \times 0,5-1 \mathrm{~mm} .58$; distome inclus : $0 \mathrm{~mm}$. $67-3 \mathrm{~mm} .50 \times 0,35-1 \mathrm{~mm} .45$. CEufs progénétiques au nombre de 25 à 50 , mesurant $78 \mu \times 49 \mu$ (Pratt, 1919).

2. Evolution probable (d'après Dickerman, 1945) :

- chez l'hôte intermédiaire (mollusque prosobranche des genres Goniobasis, Pleurocera, Campeloma) : éclosion de l'œuf mûr après ingestion - miracidium - petit sporocyste — rédies jeunes - grandes rédies où se développent les cercaires (stade libre).

- chez l'hôte définitif (poissons de la famille des Centrarchidæe) : ingestion des cercaires et développement en adultes en : 15 jours pour cercaires progénétiques ; 30 jours pour les autres.

3. Biologie :

Emission des cercaires entre 19 et 24 heures.

Résistance au froid.

Pourcentage d'infestation variable avec l'hôte et la localité (Goniobasis : 6 à $10 \%$; Pleurocera : 50 à $96 \%$ ).

4. Distribution géographique :

Wisconsin, Illinois, Alabama, Texas, Géorgie et Floride.

\section{CERCARIA HODGESIANA S. Smith 1932}

Cette cercaire a été trouvée en 1932 par S. Smith dans deux Iocalités différentes, distantes de 7 milles : Sandy Creek, Warrior River drainage, Tuscaloosa County, et Miller Springs, Cahaba River drainage, Bibb County (Alabama). Le mollusque-premier hôte est, dans les deux gîtes, Goniobasis vicina (Anthony).

La cercaire (fig. 24, a) se développe dans une rédie ressemblant à celle des autres cystocercaires.

Elle a une longueur moyenne de $3,8 \mathrm{~mm}$., avec une partie antérieure globuleuse de $1,5 \mathrm{~mm}$. de diamètre environ, contenant le dis- 
tome ; transparente et presqu'incolore, sauf dans la région où transparait le distome d'une couleur jaune très pâle, èlle semble peu apte à nager et reste habituellement fixée par sa petite fourche caudale sur le mollusque hôte ou sur quelque objet voisin, à moins

FIg. 24. - $a, C$ hodgesiana, Smith, 1932 ; $b$, Distome extrait de Cercaria hodgesiana; c, Proterometre hodgesiana Smith, 1932, adulte obtenu 120 jours après ingestion par Apomotis cyanellus (Rafinesque). Echelles de 0 à $1 \mathrm{~mm}$. (d'après S. Smith, 1936).
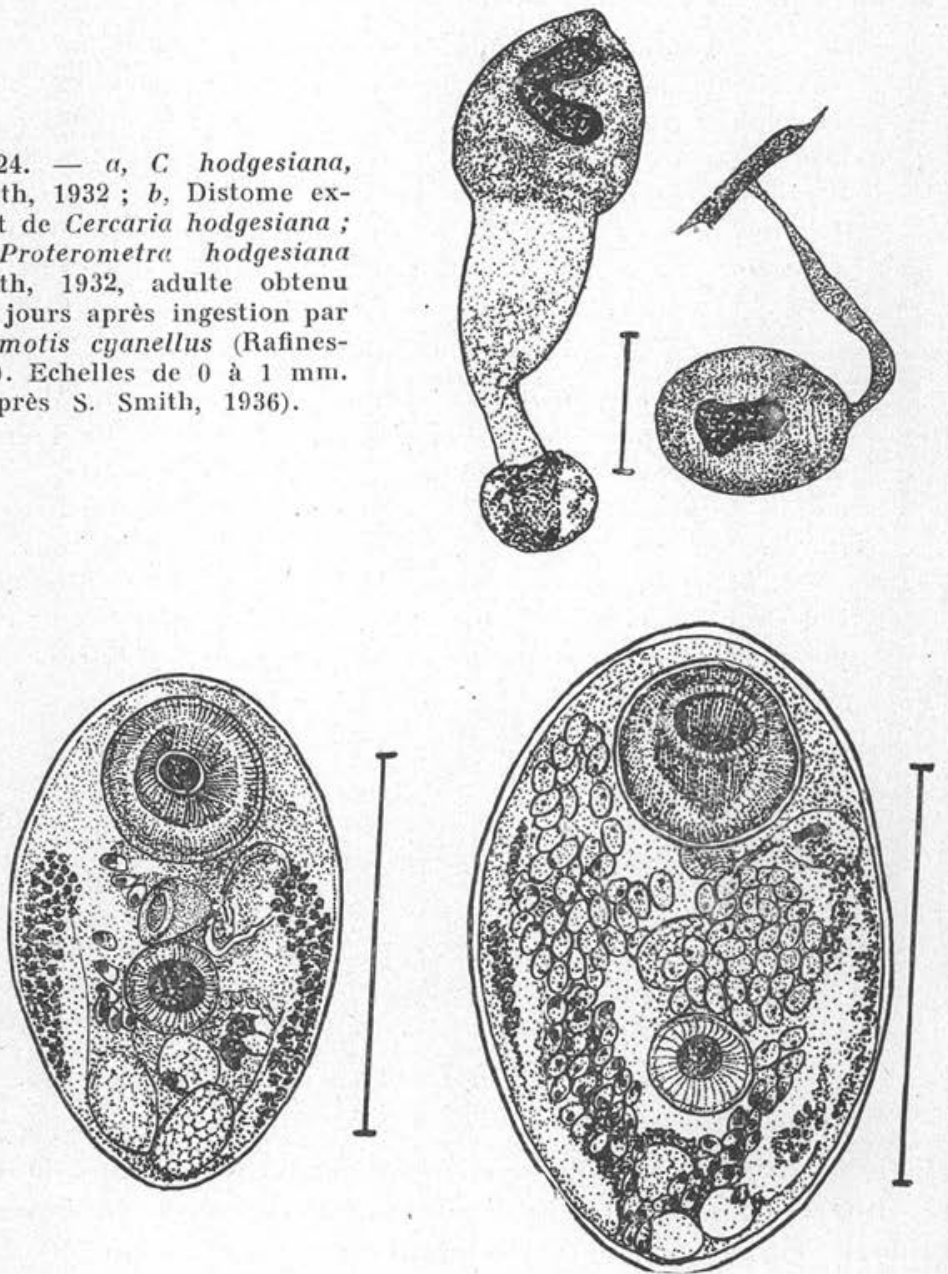

qu'elle ne demeure au fond de l'aquarium. Dans ce dernier cas, elle forme une petite masse blanche et réfringente, qui, par ses brusques mouvements en "coups de fouets », attire immédiatement l'attention des poissons. Le distome inclus dans la cercaire est très semblable à celui de $C$. macrostoma, bien qu'un peu plus petit ; i) 
mesure $1,3 \mathrm{~mm}$. de long sur $0,83 \mathrm{~mm}$. de large et emplit environ la moitié de la chambre globuleuse. Les organes occupent la même disposition que chez $C$. macrostoma (fig. $24, b$ ).

La période d'émission de ces cercaires s'étend entre 6 et $8 \mathrm{~h}$. du matin. Le pourcentage d'infestation est faible (moins de 1 p. 100).

Des infestations expérimentales de poissons appartenant à la famille des Centrarchidx furent couronnées de succès. La forme adulte subit peu de changement et se développe dans la région pharyngienne de son hòte définitif. Toutefois, un grand accroissemeat des œufs se produit au cours de leur évolution jusqu'au stade miracidium. Dans la microphotographie que donne l'auteur d'un animal adulte àgé de 120 jours (fig. $24, c$ ), obtenu chez A pomotis cyanellus (Rafinesque), on observe aisément une grande inégalité entre les œufs jeunes et les œufs mûrs, inégalité que l'auteur ne signale pas, mais sur laquelle Horsfall a vivement insisté dans sa description de Proterometra macrostoma et qui vient objectivement à l'appui de sa thèse. Cette espèce, placée dans le genre Proterometra Horsfall 1934, a été désignée par $\mathrm{S}$. Smith sous le nom de $P$. hodgesiana S. Smith 1932.

Cercaria hodgesiana et Cercaria macrostoma sont certainement des espèces très voisines. $C$. hodgesiana est caractérisée par la forme globuleuse de la partie antérieure de la queue, par l'absence de papilles spinulées, par les petites dimensions des palettes de la fourche caudale par rapport au tronc médian, enfin par sa taille habituellement inférieure à celle de $C$. macrostoma. Ce sont là les caractères différentiels qui séparent ces deux cercaires, par ailleurs biologiquement très proches.

Diagnose de Proterometra hodgesiana S. Smith 1932

1. Morphologie: dimensions moyennes:

Adulte: $1 \mathrm{~mm} 5 . \times 0 \mathrm{~mm}$. 85. Nombreux œufs dans l'utérus qui grandissent en mûrissant.

Cercaire: pas de papilles spinulées; tronc caudal: $3 \mathrm{~mm} .8 \times$

$1 \mathrm{~mm} .5$ (diam. de partie globuleuse); palettes terminales :

$0 \mathrm{~mm} .8 \times 0 \mathrm{~mm} .7$; aistome inclus: $1 \mathrm{~mm} .3 \times 0 \mathrm{~mm} .83$. Eufs progénétiques au nombre de 15-20.

2. Evolution probable: semblable à C. macrostoma.

- Hote intermédiaire: Goniobasis vicina (Anthony).

- Hôte définitif : poissons de la famille des Centrarchidx.

3. Biologie :

Emission des cercaires entre 6 et 8 heures da matin.

Pourcentage d'infestation très faible $\leqslant 1$ pour 100.

4. Distribution gécgraphique: Alabama.

Annales de Pabastologie, T. XXV, Nex $^{e x}$-6, 1950.

28. 


\section{CERCARIA CATENARIA S. Smith 1935}

Une nouvelle espèce de cystocercaire progénétique a été découverte par S. Smith, en 1935. Les mollusques parasités appartenaient,
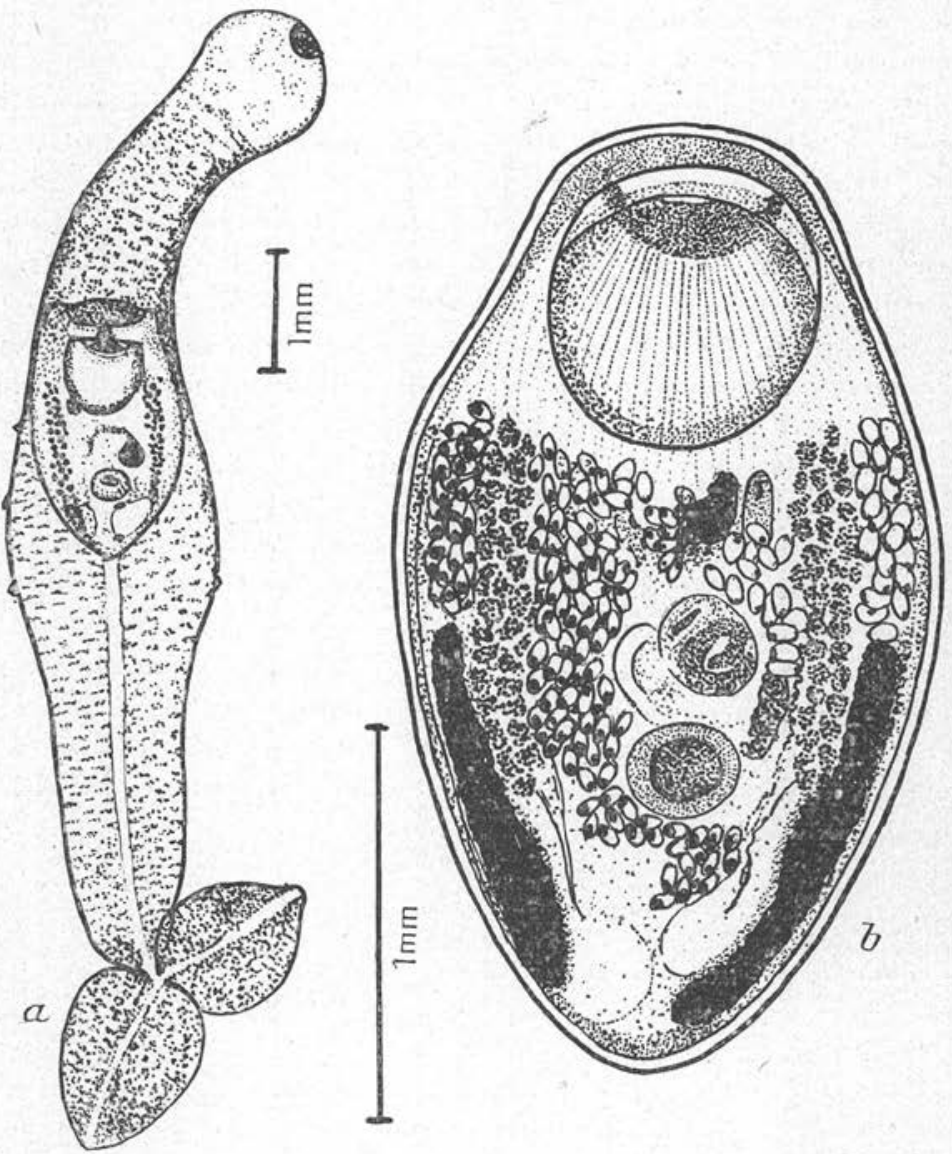

F1G. 25. - a, Cercaria catenaria Smith, 1935 ;

b, Proterometra catenaria Smith, 1935 (d'après S. Smith, 1935)

d'une part, à l'espèce Goniobasis catenaria Say, trouvée en Floride septentrionale et centrale, dans les trois systèmes de « River drainage », appelés the Apalachicola, the St-Johns et the Suwannee: d'autre part, à l'espèce Goniobasis doolyensis Lea, récoltée dans le 
"Choctwahatchee River drainage system », au sud-est de l'Alabama.

Cette cercaire mesure de 9 à $16 \mathrm{~mm}$. ; elle se meut comme une anguille, par des mouvements ondulatoires. L'animal tombe rapidement au fond de l'aquarium. Sa coloration est jaune pàle. Comme les cercaires du groupe macrostoma, elle possède des papilles spinulées, limitées à la moitié postérieure du tronc caudal. Les deux palettes terminales sont pointues (fig. 25, a).

L'émission s'effectue au cours de la journée, en général dans l'après-midi.

Cercaria catenaria se développe dans des rédies situées dans la cavité palléale du mollusque. Le distome inclus est précocement mûr, car il contient des spermatozoïdes mobiles et fonctionnc's et queiques œufs. Il se trouve presqu'au milieu du corps de la cercaire.

L'adulte a été observé chez des poissons de la famille des Centrarchidre, à la fois spontanément et expérimentalement infestés. Il a tous les caractères du genre Proterometra Horsfall, de la famille des Azygiidæx Odhner. Il doit donc être désigné sous le nom de Proterometra hodgesiana n. sp. L'adulte ne se développe guère chez l'hête définitif, sauf en ce qui concerne son activité sexuelle : c'est ainsi que plus de 400 œufs ont été dénombrés chez un poisson spontanément infesté. Les dimensions moyennes de ce trématode sont de $2,4 \mathrm{~mm}$. de long sur $1,4 \mathrm{~mm}$. de large. Les ventouses sont subsphériques, l'orale mesurant $0,64 \mathrm{~mm}$. et l'acetabulum, $0,26 \mathrm{~mm}$. de diamètre ; chez $P$. macrostoma, l'acetabulum est notablement plus grand et atteint la moitié ou plus de la ventouse orale. La disposition des autres organes ne présente guère de différences (fig. 25, b).

\section{Diagnose de Proterometra catenaria S. Smith 1935}

1. Morphologie: dimensions moyennes:

Adulte : $2 \mathrm{~mm} .4 \times 1 \mathrm{~mm}$. 4 . Nombre d'œufs dans l'utérus : environ 400, qtii grandissent en mûrissant.

Cercaire: papilles spinulées sur moitié antérieure. Tronc caudal : 9-16 mm. ; palettes pointues; distome inclus près de partie moyenne du tronc caudal ; dimensions = celles de l'adulte. Quelques œufs progénétiques.

2. Evolution :

- Hôte intermédiaire: Goniobasis catenaria Say, G. doolyensis Lea.

— Hôte définitif : poissons de la famille des Centrarchidær. Expérimentalement : Apomotis evanellus (Raf.). 


\section{Biologie :}

Emission des cercaires au cours de la journée (après-midi). Mouvements ondulatoires caractéristiques de la cercaire.

4. Distribution géographique :

Nord et Centre de la Floride, S.-E. de l'Alabama.

\section{CERCARIA SAGITTARIA E. E. Dickerman 1946}

Au cours des étés 1935, 1936 et 1937, E. E. Dickerman observa chez 32 exemplaires, parmi 15.747 Goniobasis et Pleurocera de la région de Bass Island, à l'ouest du lac Erié, une nouvelle cercaire cystocerque chez laquelle il vit jusqu'à 20 à 30 œufs. De nouvelles récoltes de Goniobasis et Pleurocera, provenant des Sandusky River, à Frémont, et Maumee River, à Grand Rapids (Ohio), firent apparaître de nouvelles infestations avec cette cystocercaire, à laquelle Dickerman donna le nom de Cercaria sagittaria n. sp. (fig. 26, C).

Le pourcentage de mollusques parasités était faible, soit un peu moins de 1 p. 100.

Les cercaires se déplacent par de lents mouvements ondulatoires et dans une faible mesure par les battements de leurs palettes. Pratiquement, elles sont volontiers sédentaires et une interprétation finaliste fait dire à l'auteur que leur mobilité doit être considérée comme une adaptation secondaire de ces organismes, en vue de leur permettre d'être aperçus par le poisson, hòte définitif, et d'y achever leur évolution.

Les émissions ont lieu durant les heures de la matinée ; les cercaires libérées sont évacuées à l'extérieur par la cavité palléale, ainsi que quelques rédies observées parfois. Elles continuent leurs moıvements caractéristiques pendant 12 à 15 heures. Puis, ces mouvements se ralentissent, consistant en une simple courbure, soit à droite, soit à gauche, les périodes d'activité alternant avec de brèves périodes de repos.

C. sagittaria est la plus grande des cercaires connues : elle peut, en effet, atteindre une longueur de 20-22 mm., en pleine extension, à l'état vivant. Elle n'est pas pigmentée, sauf au niveau du distome qui présente une coloration orangée.

Les spécimens du lac Erié sont nettement plus grands que ceux provenant de la Maumee River.

Le tronc caudal mesure de 12 à $18 \mathrm{~mm}$. de long; les palettes ont chacune de 1 à $3 \mathrm{~mm}$. de long et sont lancéolées. Le tronc s’amincit 

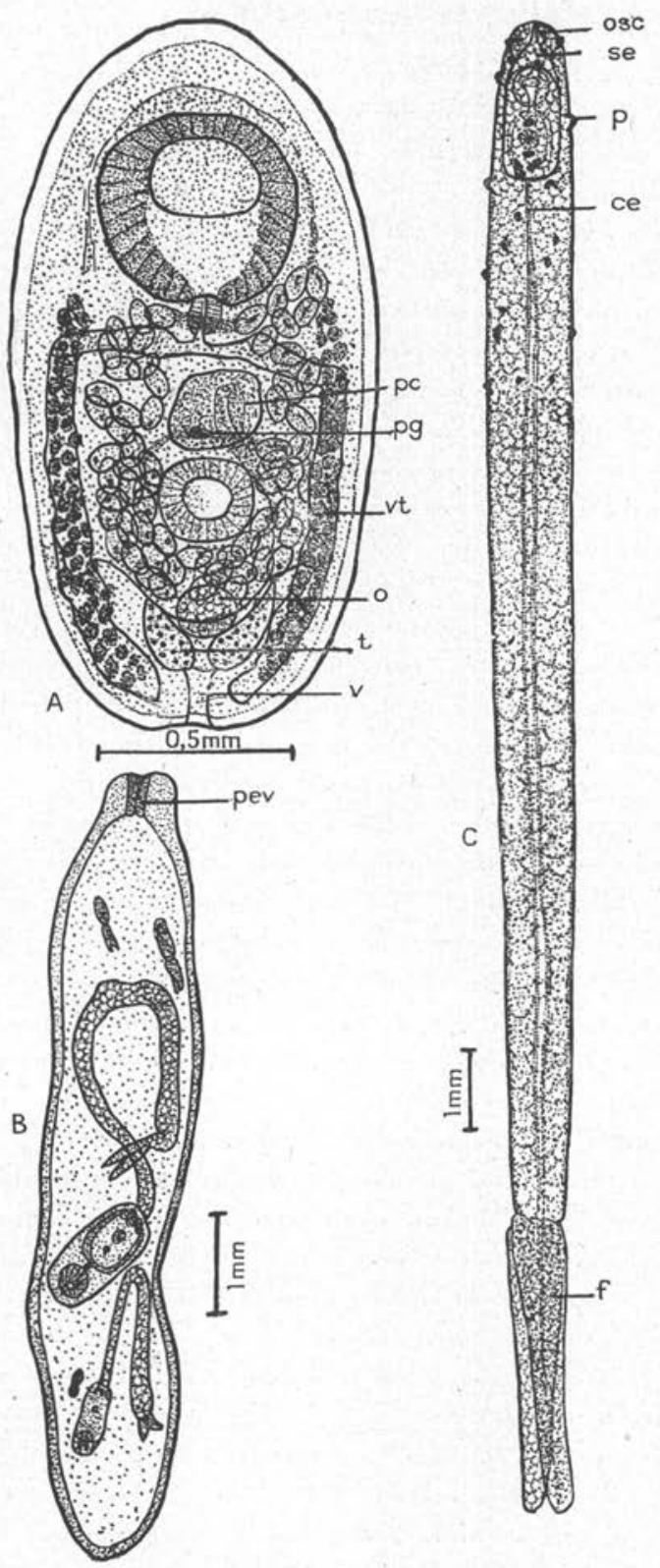

FIG. 26. - Cercaria sagiltaria et Proterometra sagittariu, 1945. B, rédic ; C, cercaire ; A, adulte. c.e. : canal excréteur ; o. : ovaire; o.s.c. : orifice de sortie de la cercaire ; p.: papilles; pal. : palettes ; p.c.: poche du cirre; p.év.: pore évacuateur ; p.g. : pore génital ; s.e. : sac embryonnaire ; $t$. : testicule ; $v$, : vessie ; vt. : vitellogènes (d'après E. E. Dickerman, 1946). 
graduellement, depuis la partie la plus large, de $1 \mathrm{~mm}$. à $1,2 \mathrm{~mm}$., qui se trouve dans la moitié antérieure. L'amincissement est surtout sensible dans la moitié postérieure. La partie la plus grèle, au point d'insertion des palettes, ne mesure que 0,3 à $0,5 \mathrm{~mm}$. de large. Ces mensurations, basées à la fois sur des animaux vivants et des spécimens fixés, beaucoup plus petits, représentent une évaluation moyenne. Le tiers antérieur est cylindrique et recouvert de rangées irrégulières de petites papilles ; il y a peu de fibres musculaires.

Le distome qui se trouve dans la cavité antérieure du tronc caudal est un adulte fonctionnel, puisqu'il possède des œufs et des spermatozoïdes dans son utérus. Il ne diffère de l'adulte que par ses dimensions et le nombre des œufs contenus dans l'utérus (fig. 26, A).

Cette cercaire est très voisine de $C$. catenaria Smith 1934. Elle s'en distingue toutefois par sa longueur plus grande et son absence de pigmentation.

Elle se développe dans des rédies botuliformes de la cavité du corps et du manteau des mollusques infestés. Les rédies vivantes sont jaune citron pâle et, à ce point de vue, tout à fait identiques à celle de $C$. macrostoma. Les rédies mûres peuvent s'allonger et atteindre $12 \mathrm{~mm}$. Les rédies jeunes de la Maumee River ont une longueur assez constante de $3,5 \mathrm{~mm}$. sur une largeur de $0,85 \mathrm{~mm}$. ; aplaties et montées, elles présentent une longueur moyenne de $5 \mathrm{~mm}$. et une largeur de $1,25 \mathrm{~mm}$. Les spécimens les plus larges du lac Erié, aplatis et montés, ont une longueur moyenne de $6,9 \mathrm{~mm}$. sur $1,8 \mathrm{~mm}$. de large (fig. $26, \mathrm{~B}$ ).

La paroi de la rédie est formée de quatre couches successives: une cuticule relativement fine, une mince couche de muscles circulaires, une mince couche de muscles longitudinaux et une couche assez épaisse de cellules parenchymateuses.

La cavité interne des grandes rédies renfermait des cercaires à tous les stades de développement, depuis les germ-balls jusqu'aux cercaires mûres produisant des œufs. Les rédies qui ont déjà évacué des cercaires contiennent aussi de nombreux œufs libres dans lesquels des miracidiums mûrs sont formés et ont éclos. Il est donc possible, dit l'auteur, que le cycle évolutif de cette forme puisse être complété sans hôte vertébré.

Les rédies les plus jeunes possèdent un pharynx et un intestin, mais, quand elles grossissent, l'intestin disparait et le pharynx, entouré par quelques fibres musculaires circulaires et longitudinales, devient le tocostome.

Dickerman fit ingérer des Cercaria sagittaria, émises par 10 Goniobasis, à 6 exemplaires d'Eupomotis gibbosus (Centrarchidæ), provenant d'une localité où ils étaient tous indemnes de parasites. Cinq 
autres poissons furent placés en présence de 15 Goniobasis émettant des Cercaria macrostoma. D'autres poissons, enfin, furent conservés comme témoins et 10 d'entre eux, après autopsie, se montrèrent négatifs.

Le 4 septembre, 26 jours après l'expérience, tous les poissons furent tués. Les témoins étaient tous négatifs. Chacun des cinq poissons mis au contact des $C$. macrostoma contenaient dans leur œsophage de un à huit adultes de Proterometra macrostoma. Les six poissons placés avec des $C$. sagittaria montrèrent dans leur œsophage de un à six adultes auxquels l'auteur donna le nom de Proterometra sagittaria n. sp.

Les trématodes adultes récoltés dans les cas décrits ci-dessus étaient à tous points de vue identiques à ceux renfermés par la cercaire, à l'exception du nombre des œufs contenus dans l'utérus qui se trouvaient en bien plus grande abondance chez les adultes trouvés chez les poissons.

Ces adultes obtenus expérimentalement, ainsi que ceux trouvés chez des poissons spontanément infestés, récoltés dans la Maumee River, étaient tous petits, mesurant seulement $3 \mathrm{~mm}$. de long en pleine extension chez l'animal vivant. Tués et légèrement aplatis, leur longueur était de $1,6 \mathrm{~mm}$. à $2 \mathrm{~mm}$. et leur largeur de $0,9 \mathrm{~mm}$. à $1 \mathrm{~mm}$.

Lorsqu'il est vivant, ce trématode est d'une teinte orangée claire qui le différencie immédiatement de la coloration beige rosée de Proterometra macrostoma. Ces deux formes se ressemblent en effet étroitement. Quand elles se rencontrent ensemble chez le même poisson, il est très facile de les distinguer gràce à leur couleur, et pratiquement ce caractère semble le plus commode pour les identifier. Elles se distinguent encore par leur musculature, la forme et les dimensions de leurs gonades, l'extension des vitellogènes et celle de l'utérus, ainsi que par les dimensions de leurs oufs, mais surtout par leur développement dans des cystocercaires essentiellement différentes.

Le rapport entre la ventouse buccale et l'acetabulum est de 2 à 1 chez Proterometra sagittaria, rapport qui reste très constant. La vésicule séminale et la glande prostatique se trouvent dans la poche du cirre. Cette vésicule est toujours bourrée de spermatozoïdes, même dans les stades de développement à l'intérieur de la rédie.

L'œuf chez l'adulte est ovale ; il possède un opercule très net. Les mensurations faites sur les œufs d'un grand nombre de spécimens donnent une moyenne de $72 \mu \times 38,5 \mu$, avec un maximum de $79 \mu \times 44 \mu$ et un minimum de $67 \mu \times 35 \mu$. Au moment de son évacuation, l'œuf renferme un miracidium non cilié, portant quatre plaques antérieures ciliées. 
Diagnose de Proterometra sagittaria, E. E. Dickerman 1946

1. Morphologie: dimensions moyennes :

Adulte : vivant, en extensicn : $3 \mathrm{~mm}$; tué, aplati : $1 \mathrm{~mm} .6$ $2 \mathrm{~mm}$. $\times 0 \mathrm{~mm}$. 9-1 mm. Nombreux œufs dans l'utérus : $72 \mu \times 38 \mu 5$. Présence d'un miracidium à 4 plaques ciliées dans les œufs mûrs.

Cercaire: papilles spinulées sur le tiers antérieur ; tronc caudal : 12-20 mm. ; palettes lancéolées : 1-3 mm. ; distome inclus : teinte orangée dans partie antérieure du tronc caudal; nombreux œufs progénétiques souvent pondus dans les rédies, contenant un miracidium mùr, qui éclôt dans la rédie.

2. Evolution :

- Hôte intermédiaire: Goniobasis et Pleurocera.

- Hôte définitif : poissons de la famille des Centrarchidæ. Expérimentalement: Eupomotis gibbosus.

3. Biologie :

Emissions de cercaires durant les heures de la matinée.

Faible motilité de la cercaire : lents mouvements ondulatoires, alternance de périodes d'activité et de repos au bout de 10-15 h.

Très faible pcurcentage d'infestation $:<1 \%$.

4. Distribution géographique: Ohio, entre lacs Michigan, Huron et Erié.

\section{CONCLUSIONS}

Depuis la création du genre Proterometra par M. W. Horsfall en 1933, pour désigner l'adulte correspondant à la première cystocercaire progénétique trouvée par Faust en 1918, trois nouvelles espèces, toutes progénétiques, s'y sont inscrites en l'espace de 13 ans, ce qui porte à quatre le nombre d'espèces par lequel ce genre est actuellement représenté : $P$. macrostoma, $P$. hodgesiana, $P$. catenaria et $P$. sagittaria. Chacune de ces espèces peut être considérée comme parfaitement valide, car l'adulte ou sa cercaire possèdent des caractéristiques constantes qui les différencient : $P$. catenaria se distingue de $P$. sagittaria par un rapport différent des deux ventouses ; celui-ci est de 2,5 à 1 chez le premier, et de 2 à 1 chez le second. Chez $P$. catenaria, les glandes vitellogènes n'atteignent jamais, en arrière, les testicules, tandis que chez $P$. macrostoma et $P$. sagittaria, elles s'étendent toujours jusqu'aux testicules. Chez $P$. sagittaria, elles peuvent même quelquefois dépasser les testicules. En ce qui concerne $P$. hodgesiana Smith 1936, l'adulte a été 
incomplètement décrit, mais, comme la cercaire dont il provient est très différente de toutes les autres cystocercaires du groupe mirabilis, il peut être considéré comme constituant une espèce valide.

$\mathrm{Si}$ nous avons donné une étude aussi détaillée de ces cystocercaires progénétiques et de leur évolution en adultes, c'est parce qu'elles nous paraissent apporter au déterminisme de la progénèse des éléments importants.

En effet, la famille à laquelle elles appartiennent, les Azygiidæ, présente déjà normalement une abréviation du cycle, puisque la cercaire ingérée par l'hôte définitif évolue directement en adulte sans passer par le stade métacercaire et sa diapause chez un second hôte intermédiaire.

D'autre part, toutes les cercaires progénétiques observées et décrites relèvent du même genre, Proterometra, ce qui semblerait prouver que, dans ce groupe de trématodes, la tendance anti-hétéroxène s'est accentuée, peut-être fixée par la sélection. Mais les facteurs extérieurs qui pourraient expliquer la progression de cette tendance n'apparaissent pas nettement. Peut-être la température a-t-elle un rôle déterminant. Il ne semble pas que ce soit une modification de la faune du bictope, une disparition plus ou moins complète des hôtes définitifs qui interviennent ici, pour favoriser une adaptation secondaire ; les espèces de Centrarchidæ sont toujours très communes dans les gìtes américains. Il ne semble pas davantage que ce soit une désaffection du distome pour son hôte définitif, car l'évolution en adultes chez le poisson a été obtenue dans tous les cas, sans difficultés majeures. La manifestation de la progénèse et l'évolution normale existent concurremment. Comment le premier processus est-il apparu, et jusqu'à quel point peut-il prendre le pas sur le second, c'est ce qui n'a pu être encore établi. En ce qui concerne le déterminisme de la ponte, rappelons seulement le cas particulier de Cercaria sagittaria: cette cercaire produit des oufs mùrs avec miracidiums vivants qui éclosent dans la rédie, aussi bien que l'adulte mûrit ses œufs chez le poisson. Si l'on considère que le distome larvaire a une taille et une morphologie tout à fait semblables à celles de l'adulte, comment ne pas l'assimiler à un adulte jeune, puisque les œufs qu'il élimine sont à maturité ?

Chez les autres cystocercaires progénétiques, la ponte semble moins évoluée et, en aucun cas, les auteurs n'ont signalé la présence d'un miracidium mûr dans les œufs de ces formes larvaires. Néanmoins, il a été démontré que les œufs utérins grossissent chez l'adulte pour atteindre, chez $P$. macrostoma par exemple, les dimensions moyennes de $82 \mu \times 49 \mu$ pour un œuf mûr. Or, les dimensions des œufs de la cercaire, données par H.-S. Pratt (1919), sont 
de $78 \mu \times 49 \mu$, chiffres bien voisins de ceux d'un œuf utérin mûr chez l'adulte. Il est donc possible que, dans certaines conditions de température et de milieu, chez la rédie de Cercaria sagittaria par exemple, les œufs progénétiques parviennent à la maturité sans le secours d'un hôte définitif.

Observons que cette tendance à la simplification du cycle évolutif n'implique pas un détachement de ces helminthes de la vie parasitaire : car, mème si l'évolution devenait monoxène, le développement du distome continuerait à se produire aux dépens de l'hòte qui l'héberge ; la partie du cycle se déroulant dans le milieu extérieur se bornerait toujours au court séjour des xufs dans la nature, avant leur ingestion par le mollusque-hôte.

(à suivre).

Institut de Parasitologie de la Facuité de Médecine de Paris et Station expérimentale de Richelieu (Indre-et-Loire)

(Directeur : Prof. H. Galliard)

(Directeir honoraire: Prof. E. Brumpt) 